OPEN ACCESS

Edited by:

Ilan Bank,

Sheba Medical Center, Israel

Reviewed by:

Buka Samten,

The University of Texas Health Science

Center at Tyler, United States

Piotr Jan Kraj,

Old Dominion University, United States

Klaus G. Schmetterer,

Medical University of Vienna, Austria

*Correspondence: Kurt Vermeire

kurt.vermeire@kuleuven.be orcid.org/0000-0003-1123-1907

Specialty section: This article was submitted to T Cell Biology,

a section of the journal

Frontiers in Immunology

Received: 07 January 2021 Accepted: 06 April 2021

Published: 21 April 2021

Citation:

Claeys E, Pauwels E, HumbletBaron S, Provinciael B, Schols D,

Waer $M$, Sprangers $B$ and Vermeire K (2021) Small Molecule Cyclotriazadisulfonamide Abrogates the Upregulation of the Human Receptors CD4 and 4-1BB and Suppresses In Vitro Activation and Proliferation of T Lymphocytes.

Front. Immunol. 12:650731. doi: 10.3389/fimmu.2021.650731

\section{Small Molecule} Cyclotriazadisulfonamide Abrogates the Upregulation of the Human Receptors CD4 and 4-1BB and Suppresses In Vitro Activation and Proliferation of T Lymphocytes

\author{
Elisa Claeys ${ }^{1}$, Eva Pauwels ${ }^{1}$, Stephanie Humblet-Baron ${ }^{2}$, Becky Provinciael ${ }^{1}$, \\ Dominique Schols ${ }^{1}$, Mark Waer ${ }^{3}$, Ben Sprangers ${ }^{4}$ and Kurt Vermeire ${ }^{1 *}$ \\ 1 KU Leuven Department of Microbiology, Immunology and Transplantation, Laboratory of Virology and Chemotherapy, Rega \\ Institute, Leuven, Belgium, ${ }^{2}$ Department of Microbiology, Immunology and Transplantation, Laboratory of Adaptive \\ Immunology, KU Leuven, Leuven, Belgium, ${ }^{3}$ Department of Microbiology, Immunology and Transplantation, Laboratory of \\ Tracheal Transplantation, KU Leuven, Leuven, Belgium, ${ }^{4}$ Department of Microbiology, Immunology and Transplantation, \\ Laboratory of Molecular Immunology, KU Leuven, Leuven, Belgium
}

The small molecule cyclotriazadisulfonamide (CADA) down-modulates the human CD4 receptor, an important factor in $T$ cell activation. Here, we addressed the immunosuppressive potential of CADA using different activation models. CADA inhibited lymphocyte proliferation with low cellular toxicity in a mixed lymphocyte reaction, and when human PBMCs were stimulated with CD3/CD28 beads, phytohemagglutinin or anti-CD3 antibodies. The immunosuppressive effect of CADA involved both $\mathrm{CD} 4^{+}$and $\mathrm{CD} 8^{+} \mathrm{T}$ cells but was, surprisingly, most prominent in the $\mathrm{CD} 8^{+} \mathrm{T}$ cell subpopulation where it inhibited cell-mediated lympholysis. Immunosuppression by CADA was characterized by suppressed secretion of various cytokines, and reduced CD25, phosphoSTAT5 and CTPS-1 levels. We discovered a direct down-modulatory effect of CADA on 4-1BB (CD137) expression, a survival factor for activated CD8 ${ }^{+} \mathrm{T}$ cells. More specifically, CADA blocked 4-1BB protein biosynthesis by inhibition of its co-translational translocation into the ER in a signal peptide-dependent way. Taken together, this study demonstrates that CADA, as potent down-modulator of human CD4 and 4-1BB receptor, has promising immunomodulatory characteristics. This would open up new avenues toward chemotherapeutics that act as selective protein down-modulators to treat various human immunological disorders.

Keywords: cyclotriazadisulfonamide (CADA), CD4 receptor, T cell activation, immunosuppression, 4-1BB (CD137), signal peptide, ER, co-translational translocation 


\section{INTRODUCTION}

The cluster of differentiation $4(\mathrm{CD} 4)$ receptor is a type I integral membrane protein consisting of four extracellular immunoglobulin-like domains, a spanning transmembrane region and a short cytoplasmic tail (1). The lymphocyte Cterminal Src kinase (Lck) non-covalently interacts with the cytoplasmic tail of CD4 (2). Next to its function in CD4 signaling, Lck inhibits endocytosis of the $\mathrm{CD} 4$ receptor by preventing the entry of CD4 into clathrin-coated pits (3). Several immune cell types express the CD4 receptor with $\mathrm{T}$ helper cells expressing the highest levels, followed by monocytes that express already 10- to 20-fold less CD4 compared to T cells (4). Studies in CD4 null mice underline the role of the CD4 receptor in positive thymic selection and development of helper $\mathrm{T}$ cells (5).

The CD4 receptor is also crucial for proper immune function, especially during $\mathrm{T}$ cell activation in which it can fulfil several roles (6). The CD4 receptor can exert an intercellular adhesion function by stabilizing the interaction between the $\mathrm{T}$ cell receptor on $\mathrm{CD} 4^{+} \mathrm{T}$ cells and the major histocompatibility complex class II on antigen-presenting cells (7). More important are the signaling function of the CD4 receptor in T cell activation through Lck and the enhancement of $\mathrm{T}$ cell sensitivity to antigens mediated by $\operatorname{CD} 4(8,9)$. Besides its role in $\mathrm{T}$ cell activation, the CD4 receptor is suggested to be involved in peripheral $\mathrm{T}$ cell differentiation towards the $\mathrm{T}$ helper 2 subset and in the chemotactic response of $\mathrm{CD}^{+} \mathrm{T}$ cells towards interleukin (IL)-16 $(10,11)$. Additionally, different functions are attributed to the $\mathrm{CD} 4$ receptor in other types of immune cells including natural killer and dendritic cells $(12,13)$. The important role of the CD4 receptor in the immune system has been further demonstrated by the in vitro and in vivo immunosuppressive potential of non-depleting anti-CD4 monoclonal antibodies (14-16).

In the field of virology, attachment of viral gp120 of human immunodeficiency virus (HIV) to the cellular CD4 receptor initiates HIV infection of target cells $(17,18)$. From an antiviral screen, the small molecule cyclotriazadisulfonamide (CADA) was identified as a potent inhibitor of HIV infection (19). The antiviral effect of this synthetic macrocycle is due to down-modulation of the $\mathrm{CD} 4$ protein, the primary entry receptor for HIV (20). This down-modulating activity of CADA is reversible in vitro: when treatment is ceased, cellular CD4 expression is rapidly restored to normal levels (21). Additionally, CADA does not compromise cellular viability as was demonstrated by long-term (about 1 year) exposure of a $\mathrm{T}$ cell line to CADA, with full recovery of $\mathrm{CD} 4$ expression when treatment was terminated (22). The sensitivity of the CD4 receptor to CADA is species-specific, as expression of murine

Abbreviations: CADA, cyclotriazadisulfonamide; CD, cluster of differentiation; CTPS1, cytidine triphosphate synthase 1; ER, endoplasmic reticulum; hCD4, human CD4; IL, interleukin; Lck, lymphocyte C-terminal Src kinase; mCD4, murine CD4; MLR, mixed lymphocyte reaction; MMF, mycophenolate mofetil; PBMC, peripheral blood mononuclear cell; PHA, phytohemagglutinin; pSTAT5, phosphorylated signal transducer and activator of transcription 5; sCD25, soluble CD25; SP, signal peptide.
CD4 (mCD4) was not affected by CADA, while primary T cells of macaques responded in a similar way as human $\mathrm{T}$ cells. Mechanistically, CADA was shown to inhibit endoplasmic reticulum (ER) co-translational translocation of the human CD4 (hCD4) pre-protein in a signal peptide (SP)-dependent way (22). CADA selectively binds to the SP of hCD4, thereby locking it in an intermediate conformation inside the Sec61 translocon channel during co-translational translocation through the ER membrane, finally resulting in proteasomal degradation in the cytosol of the mistranslocated hCD4 precursor molecules. The CADA-sensitive region of hCD4 consists primarily of the hydrophobic core of the hCD4 SP, although the presence of charged residues in the N-terminal portion of the mature protein enhances sensitivity (23). Almost no binding of CADA to the $\mathrm{mCD} 4 \mathrm{SP}$ was detected, explaining the observed resistance of mCD4 to CADA (22).

Thus, CADA down-modulates the CD4 receptor, a key component in $\mathrm{T}$ cell activation. Therefore, we explored in this study whether CADA has a potential immunomodulatory capacity. Here, CADA was evaluated in several in vitro models of $\mathrm{T}$ cell activation and was found to exert a clear immunosuppressive effect. Furthermore, in addition to the earlier reported CD4 receptor, we identified 4-1BB - a crucial co-stimulatory factor in $\mathrm{T}$ cell activation of mainly cytotoxic lymphocytes - as a new target of CADA.

\section{METHODS}

\section{Compounds and Antibodies}

CADA was a gift from Dr. Thomas W. Bell (University of Nevada, Reno). It was synthesized as described previously (24). Mycophenolate mofetil (MMF) was obtained from SigmaAldrich. Both compounds were dissolved in dimethyl sulfoxide (DMSO) to obtain a $10 \mathrm{mM}$ stock solution for use in cell culture. The anti-human CD3€ antibody (clone OKT3) used for T cell stimulation experiments was purchased from eBioscience (Thermo Fisher Scientific). The anti-CD4 monoclonal antibody Clenoliximab (chimeric macaque/human IgG4 antibody) was purchased from Absolute Antibody. Flow cytometry antibodies were purchased from (i) eBioscience (Thermo Fisher Scientific): APC-labeled anti-mouse CD4 (clone GK1.5) and APC-labeled anti-human phospho-STAT5 (Tyr694) (clone SRBCZX); (ii) BioLegend: PE-labeled anti-human CD4 (clone SK3), PElabeled anti-human CD4 (clone OKT4), APC-labeled antihuman CD4 (clone SK3) and PE-labeled anti-human CD69 (clone FN50); (iii) BD Biosciences: FITC-labeled anti-CD3 (clone UCHT-1), BV510-labeled anti-human CD8 (clone SK1), PE-labeled anti-human CD25 (clone 2A3), FITC-labeled antihuman CD25 (clone 2A3), PE-labeled anti-human CD28 (clone CD28.2), PE-labeled anti-human TCR $\alpha / \beta$ (clone IP26), PElabeled anti-human OX40 (clone ACT35), PE-labeled antihuman 4-1BB (clone 4B4-1) and BD Horizon Fixable Viability Stain 780. Western blot antibodies were purchased from (i) abcam: anti-human CTPS1 (clone EPR8086(B)); (ii) BD Biosciences: anti-human clathrin (clone 23/Clathrin Heavy 
Chain); (iii) Dako: HRP-labeled goat anti-mouse and swine antirabbit immunoglobulins.

\section{Cell Culture and Isolation}

Cell lines were obtained from the American Type Culture Collection and were maintained at $37^{\circ} \mathrm{C}$ with $5 \% \mathrm{CO}_{2}$. Jurkat, RPMI1788 and Raji-GFP cells were cultured in Roswell Park Memorial Institute 1640 medium (Gibco, Thermo Fisher Scientific) supplemented with $10 \%$ fetal bovine serum (FBS, Biowest) and $2 \mathrm{mM}$ L-glutamine (Gibco, Thermo Fisher Scientific). HEK293T cells were cultured in Dulbecco's Modified Eagle Medium (Gibco, Thermo Fisher Scientific) supplemented with 10\% FBS (Biowest) and 1\% HEPES (Gibco, Thermo Fisher Scientific). Peripheral blood mononuclear cells (PBMCs) were obtained with informed consent from anonymous healthy human donors at the Red Cross Belgium. PBMCs were isolated from buffy coats by density gradient centrifugation using Lymphoprep (Alere Technologies AS) and HetaSep (STEMCELL Technologies) to remove red blood cells. Naive $\mathrm{CD}^{+} \mathrm{T}$ cells were isolated by negative selection with the EasySep Human Naïve CD $4^{+} \mathrm{T}$ Cell Isolation Kit (STEMCELL Technologies) according to manufacturer's protocol. $\mathrm{CD}^{+}$and $\mathrm{CD}^{+} \mathrm{T}$ cells were isolated by negative selection with the Dynabeads Untouched Human CD4 T Cells Kit and the Dynabeads Untouched Human CD8 T Cells Kit (Invitrogen, Thermo Fisher Scientific) respectively, according to manufacturer's protocol.

\section{Plasmids}

The pcDNA3.1-hCD4-tGFP-P2A-mCherry construct was cloned by assembly of PCR fragments (New England BioLabs) from the pcDNA3.1 expression vector (Invitrogen, Thermo Fisher Scientific) encoding wild-type hCD4 which was kindly provided by Dr. O. Schwartz (Institut Pasteur, Paris), and the pEGFP-N1 vector (Clontech) containing EGFP-P2A-mCherry, kindly provided by Dr. R. Hegde (MRC, Cambridge). The pcDNA3.1-mCD4 expression vector was generated by cloning full-length mCD4 from a pReceiver-M16 vector, containing mouse CD4-eYFP (GeneCopoeia), into a pcDNA3.1 tGFPP2A-mCherry vector. The pcDNA3.1-hmCD4-tGFP-P2AmCherry expression vector was generated by cloning a synthesized gBlock-fragment (IDT) encoding the hCD4-mCD4 sequence into a pcDNA3.1 tGFP-P2A-mCherry vector (Invitrogen, Thermo Fisher Scientific). The other pcDNA3.1tGFP-P2A-mCherry reporter constructs were cloned by assembly of PCR fragments (New England BioLabs) from different sources: the $\mathrm{CD} 8 \alpha$ reporter construct was generated from a pORF-hCD8 $\alpha$ vector purchased from InvivoGen, while the CD25, CD28, CD69, OX40 and 4-1BB reporter constructs were cloned from vectors purchased from Sino Biological. Sequences were confirmed by automated capillary Sanger sequencing (Macrogen Europe).

\section{Cell Transfection}

HEK293T cells were plated at $5 \times 10^{5}$ cells $/ \mathrm{mL}$ in Corning Costar 6-well plates and were transfected with the tGFP-P2A-mCherry constructs $24 \mathrm{~h}$ after plating. Transfections were done by making use of Lipofectamine 2000 transfection reagent (Invitrogen, Thermo Fisher Scientific). Six hours after transfection, indicated amounts of CADA or $0.1 \%$ of DMSO were added. Cells were collected for flow cytometric analysis $24 \mathrm{~h}$ after transfection.

\section{Cell Viability Analysis}

Jurkat cells were plated at $1 \times 10^{5}$ cells/mL in Corning Costar 24well plates in the presence of indicated amounts of CADA or MMF. After 48h, cells were stained with trypan blue and counted with a Vi-CELL cell counter (Beckman Coulter).

\section{MTS-PES Assay}

Jurkat cells $\left(2.5 \times 10^{5}\right.$ cells $\left./ \mathrm{mL}\right)$ or PBMCs $\left(5 \times 10^{5}\right.$ cells $\left./ \mathrm{mL}\right)$ were plated in Falcon flat-bottom 96-well plates in the presence of indicated amounts of CADA or MMF, or in the presence of corresponding DMSO concentrations. MTS-PES (Promega) was added $48 \mathrm{~h}$ later and after a $2 \mathrm{~h}$ (Jurkat) or 24h (PBMC) incubation period, colorimetric detection was done using the VersaMax microplate reader (Molecular Devices).

\section{T Cell Activation by Superantigens}

Jurkat or naive $\mathrm{CD} 4^{+} \mathrm{T}$ cells were plated at $2.8 \times 10^{5}$ cells $/ \mathrm{mL}$ in Falcon round-bottom 96-well plates in presence or absence of 10 $\mu \mathrm{M}$ of CADA. After $48 \mathrm{~h}, \mathrm{~T}$ cells were activated by adding Staphylococcal enterotoxin E (Toxin Technology) or Staphylococcal enterotoxin B (Sigma-Aldrich)-stimulated RajiGFP cells at a concentration of $1.2 \times 10^{6}$ cells $/ \mathrm{mL}$. Raji cells were labeled with GFP to distinguish them from Jurkat and naive $\mathrm{CD}^{+} \mathrm{T}$ cells by flow cytometry. Expression of the early activation marker CD69 was detected by flow cytometry $24 \mathrm{~h}$ later. In parallel, proliferation of naive $\mathrm{CD} 4^{+} \mathrm{T}$ cells was quantified by $\left[{ }^{3} \mathrm{H}\right]$-thymidine incorporation (see protocol MLR below). For these experiments, after the loading of the Raji-GFP cells with the superantigen, Raji-GFP cells were incubated with mitomycin C (Sigma-Aldrich) to prevent their proliferation.

\section{Mixed Lymphocyte Reaction}

PBMCs $\left(1.2 \times 10^{6}\right.$ cells $\left./ \mathrm{mL}\right)$ were co-incubated with mitomycin C (Sigma-Aldrich)-inactivated RPMI1788 cells $\left(0.45 \times 10^{6}\right.$ cells/ $\mathrm{mL}$ ) in Falcon flat-bottom 96-well plates in the presence of indicated amounts of compounds or antibody and corresponding concentrations of DMSO. At day 5, $0.001 \mathrm{mCi}$ of $\left[{ }^{3} \mathrm{H}\right]$-thymidine (PerkinElmer) was added per well and $18 \mathrm{~h}$ later, cells were harvested on Unifilter-96 GF/C plates (PerkinElmer) with the Unifilter-96 Cell Harvester (PerkinElmer). $20 \mu \mathrm{L}$ of MicroScint-20 (PerkinElmer) was added per filter and counts per minute (cpm) were detected with the MicroBeta device (PerkinElmer). Expression of hCD4 was measured at day 5 by flow cytometry.

\section{Cell-Mediated Lympholysis}

PBMCs $\left(4.8 \times 10^{6}\right.$ cells $\left./ \mathrm{mL}\right)$ were co-incubated with mitomycin C (Sigma-Aldrich)-inactivated RPMI1788 stimulator cells (1.8 x $10^{6}$ cells $/ \mathrm{mL}$ ) in Falcon round-bottom $14 \mathrm{~mL}$ tubes in presence or absence of CADA for 6 days. After this incubation period, PBMCs were collected and concentrated at $5 \times 10^{6}$ cells $/ \mathrm{mL}$. 
Fresh target RPMI1788 cells were labeled with ${ }^{51} \mathrm{Cr}$ (MP Biomedicals), followed by a $4 \mathrm{~h}$ incubation at $37^{\circ} \mathrm{C}$ with the PBMCs in a ratio of 50/1 (500,000 effector cells/10,000 target cells per well). To measure spontaneous and maximum release of ${ }^{51} \mathrm{Cr}$, medium or saponin was added to the ${ }^{51} \mathrm{Cr}$-labeled RPMI1788 cells, respectively. After incubation, supernatant was collected and ${ }^{51} \mathrm{Cr}$ release was detected using a TopCount gamma counter (Packard Instrument Company). The percentage of specific lysis was calculated by the following formula: \% specific lysis $=($ experimental release - spontaneous release $) /$ (maximum release - spontaneous release) x 100 .

\section{T Cell Activation by CD3/CD28 Beads, Phytohemagglutinin or Anti-CD3 Abs}

PBMCs were pre-incubated at a concentration of $4 \times 10^{5}$ cells $/ \mathrm{mL}$ with $10 \mu \mathrm{M}$ of CADA or $0.1 \%$ DMSO for 2 hours or 3 days in Falcon flat-bottom 96-well plates. T cells were activated with Dynabeads Human T-Activator CD3/CD28 (beads/cell ratio of 1/2; Gibco, Thermo Fisher Scientific), with $4.5 \mu \mathrm{g} / \mathrm{mL}$ phytohemagglutinin (PHA; Sigma-Aldrich), or with $1 \mu \mathrm{l}$ of anti-CD3 antibody (aCD3; eBioscience; $0.5 \mathrm{mg} / \mathrm{ml}$ ) per $4 \times 10^{5}$ cells, and further incubated with $10 \mu \mathrm{M}$ of CADA or $0.1 \%$ DMSO. At $4 \mathrm{~h}, 1$ day, 2 days, 3 days or 4 days after activation, $0.001 \mathrm{mCi}$ of $\left[{ }^{3} \mathrm{H}\right]$-thymidine (PerkinElmer) was added per well and $22 \mathrm{~h}$ later, cells were harvested on Unifilter-96 GF/C plates (PerkinElmer) with the Unifilter-96 Cell Harvester (PerkinElmer). $20 \mu \mathrm{L}$ of MicroScint-20 (PerkinElmer) was added per filter and cpm were detected with the MicroBeta device (PerkinElmer). Expression of CD4, CD8, CD25 and CD28 was measured by flow cytometry just before activation (0h) and 4h, 1 day, 2 days, 3 days or 4 days after activation. Expression of OX40 and 4-1BB was measured by flow cytometry 2 days after activation. Intracellular levels of phosphorylated signal transducer and activator of transcription 5 (pSTAT5) were measured by flow cytometry 2 days after activation with or without an extra stimulation with $25 \mathrm{ng} / \mathrm{mL}$ IL-2 (R\&D Systems) during $15 \mathrm{~min}$.

\section{Flow Cytometry}

Cells were collected and washed in PBS (Gibco, Thermo Fisher Scientific) supplemented with 2\% FBS (Biowest). Antibodies were diluted in PBS with 2\% FBS and samples were stored in PBS containing $1 \%$ formaldehyde (VWR Life Science AMRESCO). For intracellular staining, samples were immediately fixed in PBS with $2 \%$ formaldehyde, after which cells were permeabilized using absolute methanol (Biosolve) and stained with antibody. For the flow cytometry experiments of (activated) PBMCs, a viability stain (BD Horizon Fixable Viability Stain 780) was standard included to discriminate living from dead cells. Subsequent analysis was performed on gated living, single cells only. Acquisition of all samples was done on a BD FACSCanto II flow cytometer (BD Biosciences) with BD FACSDiva v8.0.1 software, except for the samples of the tGFP-P2A-mCherry constructs, that were acquired on a BD LSRFortessa flow cytometer (BD Biosciences) with BD FACSDiva v8.0.2 software. Flow cytometric data were analyzed in FlowJo v10.1.

\section{ELISA and Bio-Plex Assay}

For detection of soluble CD25 (sCD25), supernatants were collected at 2 days, 3 days or 4 days after activation with CD3/ CD28 beads or PHA. The concentration of sCD25 was measured with the Human CD25/IL-2R alpha Quantikine ELISA kit (R\&D Systems) according to manufacturer's protocol. Detection was done using a SpectraMax Microplate Reader (Molecular Devices). For the quantification of the cytokines Cytokine Human ProcartaPlex Panel kits (Invitrogen, Thermo Fisher Scientific) were used following manufacturer's protocol. Supernatant was taken at day 5 post stimulation for the MLR samples and at day 3 for the CD3/CD28 beads- and PHAactivated samples. Detection was done with the Bio-Plex 200 System (Bio-Rad).

\section{Western Blot}

PBMCs were lysed in ice-cold Nonidet P-40 buffer (50 mM Tris$\mathrm{HCl}$ ( $\mathrm{pH} 8.0$ ), $150 \mathrm{mM} \mathrm{NaCl}, 1 \%$ Nonidet P-40) supplemented with 100x cOmplete Protease Inhibitor Cocktail (Roche, SigmaAldrich) and 250x PMSF Protease Inhibitor (100 mM in dry isopropanol, Thermo Fisher Scientific) and centrifuged at $17,000 x$ during $10 \mathrm{~min}$. Samples were boiled in reducing $2 \mathrm{x}$ Laemmli sample buffer (120 mM Tris- $\mathrm{HCl}$ (pH 6.8), 4\% sodium dodecyl sulphate, $20 \%$ glycerol, $100 \mathrm{mM}$ dithiothreitol, $0.02 \%$ bromophenol blue) and were separated on $4-12 \%$ Criterion XT Bis-Tris Precast gels (Bio-Rad) using 1x MES buffer (Bio-Rad). After electrophoresis, gels were blotted onto polyvinylidene difluoride membranes with the Trans-Blot Turbo Transfer System (Bio-Rad). Membranes were blocked during $1 \mathrm{~h}$ with $5 \%$ nonfat dried milk in tris-buffered saline with Tween 20 (20 $\mathrm{mM}$ Tris- $\mathrm{HCl}$ (pH 7.6), $137 \mathrm{mM} \mathrm{NaCl}, 0.05 \%$ Tween 20) and incubated overnight with the primary antibodies at $4^{\circ} \mathrm{C}$. The next day, membranes were washed and incubated with the secondary antibodies. Detection was done with a ChemiDoc MP Imaging System (Bio-Rad) using the SuperSignal West Femto Maximum Sensitivity Substrate (Pierce, Thermo Fisher Scientific). Clathrin was used as a control for protein concentration.

\section{Cell-Free In Vitro Translation and Translocation}

The Qiagen EasyXpress linear template kit was used to generate full length cDNAs using PCR.

PCR products were purified and transcribed in vitro using T7 RNA polymerase (RiboMAX system, Promega). All transcripts were translated in rabbit reticulocyte lysate (Promega) in the presence of L-35S-methionine (Perkin Elmer). Translations were performed at $30^{\circ} \mathrm{C}$ in the presence or absence of ovine pancreatic microsomes and CADA as described elsewhere (25). Samples were washed with low-salt buffer ( $80 \mathrm{mM}$ KOAc, $2 \mathrm{mM} \mathrm{Mg(OAc)2,} 50 \mathrm{mM}$ HEPES $\mathrm{pH}$ 7.6) and radiolabeled proteins were isolated by centrifugation for 10 minutes at $21,382 \times \mathrm{g}$ and $4^{\circ} \mathrm{C}$ (Hettich $200 \mathrm{R}$ centrifuge with 2424-B rotor). The proteins were then separated with SDSPAGE and detected by phosphor imaging (Cyclone Plus storage phosphor system, Perkin Elmer). 


\section{Statistical Analysis}

Data were visualized as means \pm standard deviation (SD) or as absolute individual data points and were analyzed by making use of the GraphPad Prism v7.0 software. Data were analyzed with multiple t-tests to compare different treatment concentrations to the corresponding control or to compare CADA to DMSO in several stimulation conditions. In case of multiple testing, a Holm-Sidak method was used to correct for multiple comparison. Paired t-tests were used for the comparison of CADA and DMSO for proliferation response, receptor expression and levels of sCD25 at certain time points. P-values bellow 0.05 were considered statistically significant.

\section{RESULTS}

\section{CADA Down-Modulates the Human CD4 Receptor and Has an Immunosuppressive Effect in the Mixed Lymphocyte Reaction}

In line with our previous report (22), the small molecule CADA dose-dependently down-modulated the hCD4 receptor on Jurkat $\mathrm{T}$ cells as well as on human peripheral blood mononuclear cells (PBMCs) (Figure 1A). At a concentration of $10 \mu \mathrm{M}$ CADA, the cell surface hCD4 expression level was greatly reduced in both cell types: $86 \%$ reduction in hCD4 expression for Jurkat cells and $74 \%$ for PBMCs, as compared to untreated control cells ( IC $_{50}$ values of $0.41 \mu \mathrm{M}$ and $0.94 \mu \mathrm{M}$, respectively). Based on this hCD4 receptor down-modulating potency of CADA, we addressed whether CADA has a potential immunomodulatory capacity in human cells. In a first approach, the effect of CADA was evaluated in Jurkat $\mathrm{T}$ cells activated in vitro by means of superantigens. Activation was assessed by measuring the expression of the early activation marker CD69. Whereas Jurkat $\mathrm{T}$ cells barely responded to staphylococcal enterotoxin B (SEB), they were highly activated by the superantigen staphylococcal enterotoxin E (SEE), as evidenced by the profound CD69 expression (Supplementary Figure 1A). Treatment with CADA resulted in a partial reduction in CD69 levels (35\% reduction in MFI), although a substantial subset of cells remained highly activated in the presence of CADA (Supplementary Figures 1A, B). Next, naïve $\mathrm{CD}^{+} \mathrm{T}$ cells (isolated from PBMCs of healthy donors) were exposed to superantigens in the absence or presence of CADA. An appreciable subpopulation of naïve $\mathrm{CD}^{+} \mathrm{T}$ cells became activated after triggering by SEB, as evidenced by the massive CD69 expression (Figure 1B). Although pre-treatment with CADA clearly reduced CD4 levels, the impact of CADA on CD69 upregulation was only limited. More specifically, in the presence of CADA the number of $\mathrm{CD}^{+} 9^{+}$activated cells was reduced by $9 \%$ (Figure 1 C), but the degree of activation, deduced from the CD69 expression level, was unaffected by CADA in the superantigen-responding naïve $\mathrm{CD}^{+} \mathrm{T}$ cells (Figure 1B; histogram plot). Additional analysis of cell proliferation (quantified by $\left[{ }^{3} \mathrm{H}\right]$-thymidine incorporation) confirmed the minor impact of CADA on the superantigen-induced activation of naïve $\mathrm{CD} 4^{+} \mathrm{T}$ cells (Figure 1D).
Importantly, CADA significantly inhibited lymphocyte proliferation in the mixed lymphocyte reaction (MLR), an in vitro assay in which PBMCs are co-cultured with mitomycininactivated stimulator B cells that represents a more physiological relevant model of $\mathrm{T}$ cell stimulation (Figure 1E). Although lymphocyte proliferation was not blocked completely, there was a strong dose-dependent inhibitory effect of CADA. The antiproliferative immunosuppressive agent mycophenolate mofetil (MMF), included as control, evoked a stronger maximal inhibitory effect, with complete inhibition of lymphocyte proliferation at a dose of $2 \mu \mathrm{M}$ of MMF and higher (Figure 1E). In contrast to MMF, the observed suppression of $\mathrm{T}$ cell proliferation by CADA in the MLR was not related to enhanced cellular toxicity, as evidenced by similar levels of metabolic activity in CADA treated PBMCs and DMSO controls (Figure 1F). Accordingly, viability of Jurkat cells cultured in the presence of CADA was not affected for concentrations up to $50 \mu \mathrm{M}$, and only a small reduction in metabolic activity was observed for higher doses of CADA that reached significance at a concentration of $50 \mu \mathrm{M}$ (Supplementary Figure 1C).

\section{Reduced CD4 Surface Expression Affects Lymphocyte Proliferation in the MLR}

As CADA down-modulates the hCD4 receptor, we next investigated if reduced cell surface CD4 expression correlates with inhibition of lymphocyte proliferation observed in the MLR. Therefore, we compared CADA with another agent that directly targets the hCD4 receptor, namely the non-depleting anti-CD4 monoclonal antibody Clenoliximab (26). PBMCs were co-cultured with mitomycin-inactivated RPMI1788 cells in the presence of the compound, and at day five, the sample was evaluated for CD4 expression by flow cytometry. In parallel, an identical sample was exposed to $\left[{ }^{3} \mathrm{H}\right]$-thymidine to measure the proliferation response $18 \mathrm{~h}$ later. Clenoliximab evoked a CD4 down-modulating effect but this was less effective and more variable as compared to CADA (Supplementary Figure 2), and had an inhibitory effect on lymphocyte proliferation, although rather limited (about 30\% reduction). For CADA, a clear dose-dependent inhibition of lymphocyte proliferation was observed, however, whereas CD4 reduction plateaued at $2 \mu \mathrm{M}$ of CADA, a steady decrease in lymphocyte proliferation was measured with increasing doses of CADA (Supplementary Figure 2). This suggests that for CADA (an) additional immunomodulatory effect(s) are at play beyond suppression of CD4 receptor expression.

\section{CADA Suppresses Lymphocyte Proliferation and Inhibits Upregulation of CD4 and CD8 After Activation by CD3/ CD28 Beads or PHA}

To further explore the inhibitory effect of CADA and CD4 downmodulation on lymphocyte proliferation, we evaluated CADA in two additional in vitro models of $\mathrm{T}$ cell activation. The first one, referred to as $\mathrm{CD} 3 / \mathrm{CD} 28$ beads stimulation assay, is based on the use of inert, superparamagnetic beads to which anti-CD3 and anti-CD28 antibodies are covalently coupled. The second model is by addition of phytohemagglutinin (PHA), a lectin that binds 
A
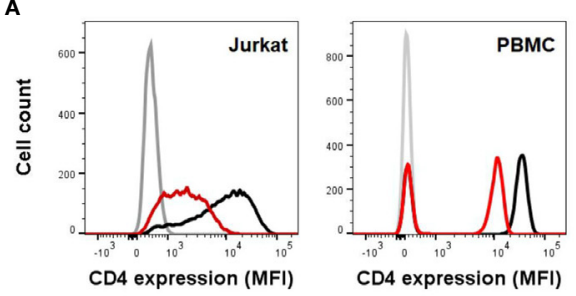

B

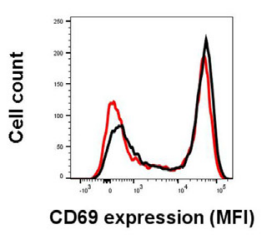

E

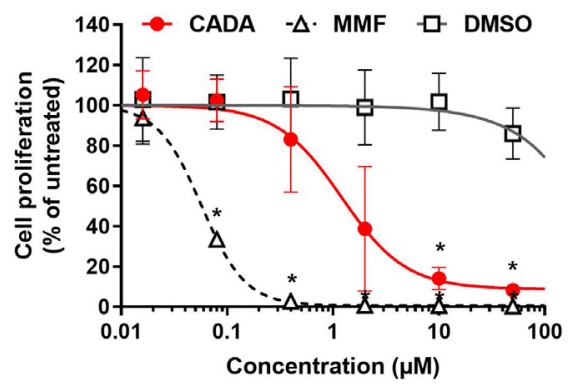

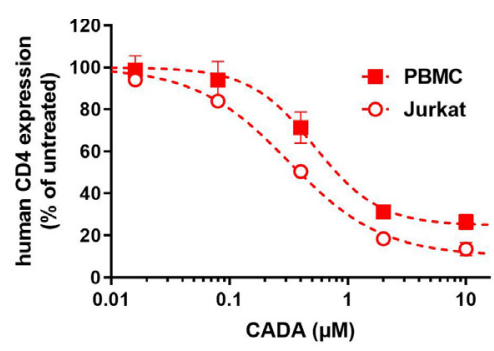

C

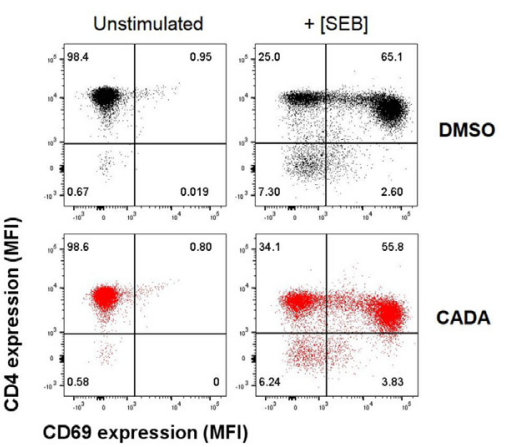

D
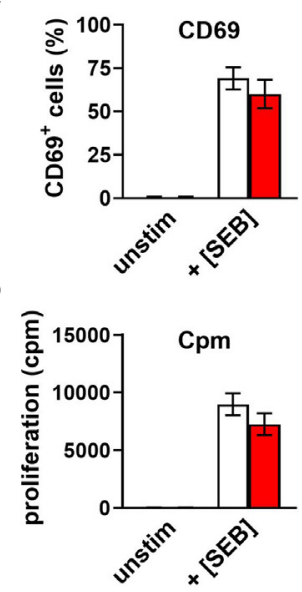

FIGURE 1 | CADA down-modulates the human CD4 receptor and has an immunosuppressive effect in the mixed lymphocyte reaction. (A) Representative flow cytometry histogram plots are given for cell surface human CD4 in Jurkat cells and PBMCs treated with DMSO or CADA (2 $\mu$ M). Control cells are depicted in black, CADA-treated cells in red, and unstained controls in grey. Cells were incubated with CADA and CD4 expression was measured using a PE-labeled anti-human CD4 antibody (clone SK3) after 2 days for Jurkat cells or 5 days for PBMCs. The graph shows relative CD4 expression in CADA-treated cells, based on the Mean Fluorescence Intensity (MFI) values for CD4 (acquired from at least 10,000 cells per experiment) and calculated as percentage of untreated control (mean \pm SD). Four parameter dose-response curves are given for CADA, calculated from 3 independent experiments $(n=3)$. (B) Naive CD4 ${ }^{+} T$ cells were pre-treated with CADA (10 $\mu$ M) for 3 days and subsequently stimulated with mitomycin C inactivated Raji-GFP cells loaded with staphylococcal enterotoxin B (SEB). CD69 and CD4 expression was measured 24h later. Histogram plot represents the CD69 expression of naive CD4 ${ }^{+} \mathrm{T}$ cells, with control cells indicated in black and CADA-treated cells in red. Dot plots from a representative donor show CD4 and CD69 double staining on unstimulated and stimulated cells at 24h post activation. (C) Same as in (B), but the CD69 positive cells were quantified and calculated as percentage of total cell population. Bar diagrams are showing the amount of CD69 positive cells on day 1 post activation with DMSO in white and CADA in red. Values represent mean \pm SD of four different donors ( $n=4)$. (D) Naive CD4 ${ }^{+}$T cells were pre-treated with CADA (10 $\mu \mathrm{M})$ for 3 days and subsequently stimulated with mitomycin $\mathrm{C}$ inactivated Raji-GFP cells loaded with SEB. At day 2 post activation, $\left[{ }^{3} \mathrm{H}\right]$-thymidine was added and proliferation response was measured by detecting cpm 18h later. Bar diagrams are showing cpm values with DMSO in white and CADA in red. Values represent mean \pm SD of two different donors $(n=2)$. (E) PBMCs were co-cultured with mitomycin $\mathrm{C}$ inactivated RPMl1788 cells in the presence of CADA, MMF or matching DMSO concentrations. At day 5, [ $\left.{ }^{3} \mathrm{H}\right]$-thymidine was added and proliferation response was measured $18 \mathrm{~h}$ later by detecting counts per minute. Lymphocyte proliferation is given as percentage of untreated control. Multiple t-tests were performed to compare each concentration of CADA or MMF to the corresponding DMSO control with ${ }^{*} \mathrm{p}<0.05$ and with Holm-Sidak method as correction for multiple comparison. Curves are showing mean values \pm SD of four different donors $(n=4)$. (F) PBMCs were stimulated with PHA for 3 days and were subsequently exposed to different concentrations of CADA, MMF or DMSO. After 2 days of drug treatment, MTS-PES was added to measure cellular metabolic activity, and read-out was done 24h later on a spectrophotometer. Metabolic activity of cells is given as percentage of untreated control. Multiple t-tests were performed to compare each concentration of CADA or MMF to the corresponding DMSO control with ${ }^{*} p<0.05$ and with Holm-Sidak method as correction for multiple comparison. Curves are showing mean values \pm SD of four different donors ( $\left.n=4\right)$. (E) See also Supplementary Figures 1 and 2. 
to sugars on glycosylated surface proteins, including the TCR and CD3, thereby crosslinking them. Briefly, PBMCs were preincubated with a fixed dose of CADA $(10 \mu \mathrm{M})$ or DMSO control for 3 days to obtain reduced cell surface CD4 levels, and were subsequently activated by CD3/CD28 beads or PHA. In both models, the proliferation response of lymphocytes in the control samples steadily increased over time in all donors, with a peak at day 3 post activation (Figure 2A; open symbols). Treatment with CADA suppressed the responsiveness of lymphocytes to both CD3/CD28 beads and PHA (Figure 2A; red solid symbols). Intra-donor analysis revealed that CADA significantly reduced cell proliferation compared to DMSO control in both models at day 1 and 2 post activation.

In addition to the proliferation response, we analyzed the expression level of cell surface CD4 and CD8, receptors known to be involved in $\mathrm{T}$ cell activation. As expected, basal CD4 expression on $\mathrm{CD}^{+} \mathrm{T}$ cells measured at time point 0 , which is after 3 days of CADA pre-incubation, was decreased by half in the CADA-treated samples (Figure 2B and Supplementary Figure 3A). In control $\mathrm{CD}^{+} \mathrm{T}$ cells (treated with DMSO) cell surface CD4 expression was strongly upregulated starting from day 1 post activation by CD3/CD28 beads and by PHA (Figure 2B). In sharp contrast, in both activation models CADA completely blocked this induced CD4 upregulation in all donors and at every tested time point (Figure 2B and Supplementary Figure 3A), a result of the complete inhibition of hCD4 protein biogenesis by CADA (22). In the $\mathrm{CD}^{+} \mathrm{T}$ cell population, basal CD8 expression was also partially affected by pre-treatment with CADA (Figure 2C and Supplementary Figure 3A). Intra-donor flow cytometric analysis of the samples revealed that the mean fluorescence intensity (MFI) for CD8 receptor expression in the CADA-treated cells was reduced by $38 \pm 4 \%$ (mean \pm SD; Supplementary Figure 3A, $\mathrm{d} 0$ ). After activation by CD3/CD28 beads and PHA, CD 8 expression was upregulated in the control samples, starting at day 1 and with a continuous increase over the next days. Exposure of the cells to CADA clearly suppressed this activation-triggered CD8 upregulation (Figure 2C). However, from day 3 onwards, CD8 levels started to rise in the CADAtreated samples, which was most prominent in the PHAstimulated cells (Figure 2C, right panel). Consequently, the suppression of CADA on CD8 receptor upregulation in these cells plateaued around 50\% (Supplementary Figure 3A).

In contrast to CD4 and CD8, basal expression levels of CD3 and TCR in PBMCs or PHA-blasts were not affected by CADA (Figures 2D, E and Supplementary Figure 3B), indicating that CADA has no direct effect on these proteins. However, 2 days after activation with $\mathrm{CD} 3 / \mathrm{CD} 28$ beads and $\mathrm{PHA}$, cell surface levels of CD3 and TCR were approximately 20 to $30 \%$ lower in the CADA pre-treated samples (Supplementary Figure 3C). This inhibition of CD3 and TCR upregulation after exposure to the immune stimulus is most likely because of a secondary effect of the immunosuppressive activity of CADA. In addition, the expression of the early activation marker CD69 was assessed. Although in some donors there was a tendency of reduced CD69 levels in the CADA treated samples (Supplementary
Figure 3D), the high interdonor variability resulted in less conclusive CD69 data (Supplementary Figure 3E).

\section{CADA Dose-Dependently Inhibits CD8 ${ }^{+}$ $T$ Cell Proliferation and Cytotoxic T Cell Function}

As CADA treatment also resulted in lower expression of the CD8 receptor on $\mathrm{CD}^{+} \mathrm{T}$ cells, the effect of CADA on $\mathrm{CD}^{+} \mathrm{T}$ cell function was further examined. To this purpose, an MLR was performed with total PBMCs, purified $\mathrm{CD} 4^{+} \mathrm{T}$ cells or purified $\mathrm{CD}^{+} \mathrm{T}$ cells. Generally, the proliferation response of purified $\mathrm{CD}^{+} \mathrm{T}$ cells was much weaker for each donor in comparison to the proliferation response of purified $\mathrm{CD}^{+} \mathrm{T}$ cells (data not shown). As demonstrated in Figure $3 \mathbf{A}$, CADA dosedependently suppressed the proliferation of purified $\mathrm{CD}^{+} \mathrm{T}$ cells, although to a lesser extent as compared to total PBMCs. Remarkably, CADA profoundly and dose-dependently inhibited the proliferation of purified $\mathrm{CD}^{+} \mathrm{T}$ cells, in a similar way as that of total PBMCs. In addition, the proliferation of purified $\mathrm{CD} 8^{+} \mathrm{T}$ cells by beads or PHA stimulation was clearly suppressed by CADA (Figure 3B). This indicates that the suppressive effect of CADA on lymphocyte activation is mostly affecting the CD8 ${ }^{+}$ subpopulation and, thus, independent of CD4 expression.

Next, to evaluate the effect of CADA on the cytotoxic potential of $\mathrm{CD}^{+} \mathrm{T}$ cells, a cell-mediated lympholysis assay was performed. Briefly, PBMCs were cultured in medium alone or were co-cultured with mitomycin C-inactivated RPMI1788 cells in the absence or presence of CADA for 6 days. These PBMCs were then exposed to ${ }^{51} \mathrm{Cr}$-loaded RPMI1788 cells for $4 \mathrm{~h}$, after which supernatant was collected to quantify ${ }^{51} \mathrm{Cr}$ release, reflecting the lysis of RPMI1788 cells. PBMCs cultured in medium without stimulator cells did not show notable cytotoxic activity (3\% of specific lysis; black bar in Figure 3C). However, when PBMCs were co-cultured with RPMI1788 cells, cytotoxic activity increased considerably (71\% of specific lysis; white bar in Figure 3C). Interestingly, treatment with CADA reduced this cytotoxic response dose-dependently $(77 \%$ inhibition of specific lysis with $50 \mu \mathrm{M}$ of CADA, and $53 \%$ with $10 \mu \mathrm{M}$ of CADA; red bars in Figure 3C). At lower concentrations of CADA, cell-mediated lympholysis was no longer inhibited.

\section{CADA Affects Cytokine Release by Activated PBMCs}

Our first set of data indicated that CADA attenuates the general activation of $\mathrm{T}$ lymphocytes. To explore the suppressive effect of CADA in more detail, we next analyzed the impact of CADA on the cytokine release by the proliferating lymphocytes. Supernatant was taken from PBMCs either stimulated by mitomycin C inactivated RPMI1788 cells (MLR), CD3/CD28 beads or PHA and analyzed for representative Th1, Th2 and Th17 cytokines. As summarized in Figure 4, CADA generally suppressed the level of IL-2, IFN- $\gamma$, TNF- $\alpha$ and IL- 4 in the three activation models, which reached significance for the cytokines detected in the MLR samples. TNF- $\alpha$ was significantly reduced by CADA treatment in all three models ( $<<0.05$; $t$-test). In the 


\section{$\mathrm{CD} 3 / \mathrm{CD} 28$}

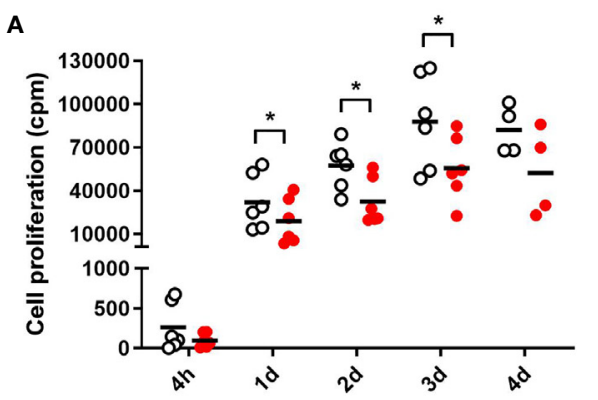

B

C
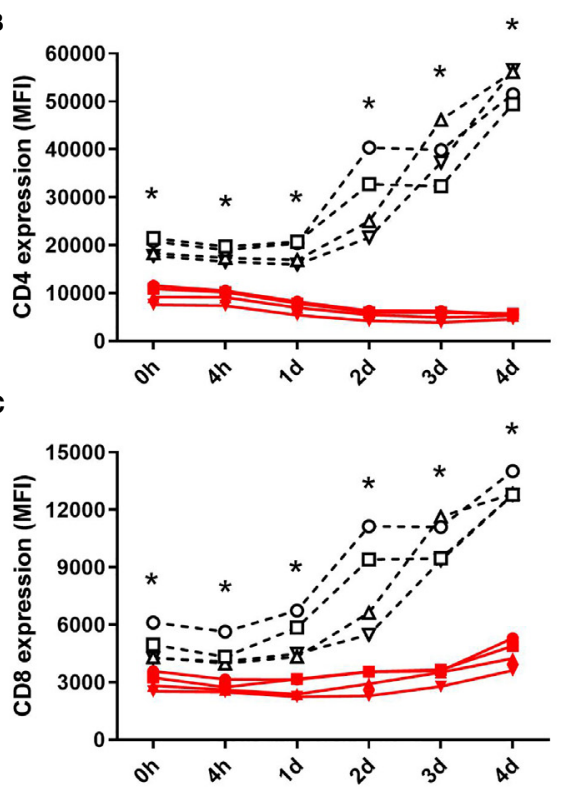

。

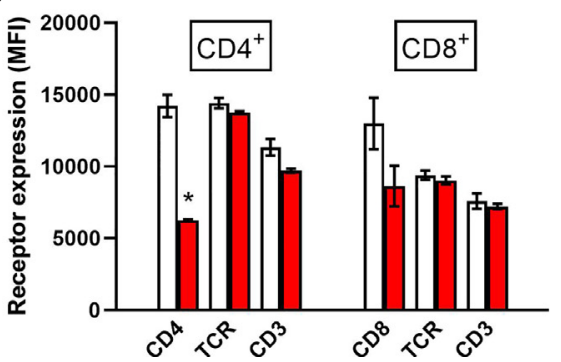

PHA
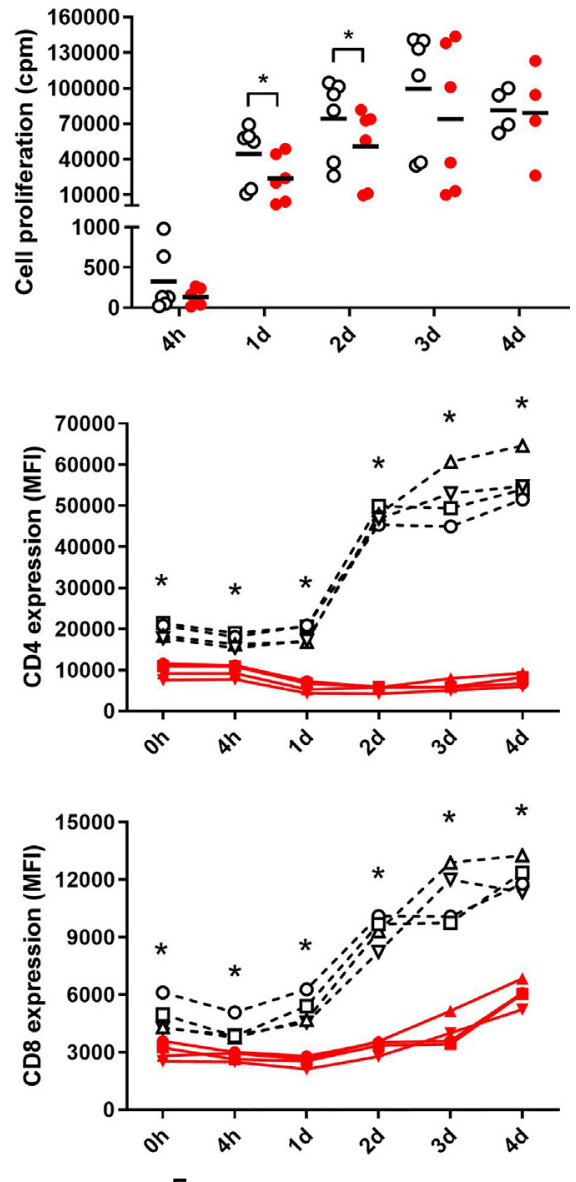

E

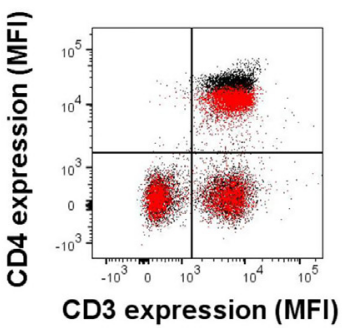

FIGURE 2 | CADA suppresses lymphocyte proliferation and inhibits upregulation of CD4 and CD8 after activation by CD3/CD28 beads or PHA. (A) PBMCs were pre-incubated with CADA $(10 \mu \mathrm{M})$ or DMSO during 3 days, after which they were activated by CD3/CD28 beads (left panels) or PHA (right panels). At 4h, 1d, 2d, 3d or $4 \mathrm{~d}$ post activation, $\left[{ }^{3} \mathrm{H}\right]$-thymidine was added and proliferation response was measured by detecting counts per minute (cpm) $22 \mathrm{~h}$ later. Individual $\mathrm{cpm}$ values are shown for stimulated PBMCs with DMSO-treated cells as open symbols and CADA-treated cells as solid red dots. A paired t-test was performed to compare CADA to DMSO with ${ }^{*} p<0.05$. Horizontal lines indicate the mean values of 4 to 6 donors $(n=6$, except for time point $4 d$ where $n=4)$. (B, C) Cell surface CD4 (B) and CD8 (C) receptor expression was measured by flow cytometry just before activation (Oh) and 4h, 1d, 2d, 3d or 4d post activation with CD3/CD28 (left) or PHA (right). Mean fluorescence intensity (MFI) of human CD4 or CD8 receptor expression is shown for different donors of PBMCs (indicated separately) with DMSO-treated samples as a black dotted line and CADA-treated samples as a red line. Curves are showing single MFI values of the indicated receptor (acquired from at least 5,000 cells per donor) for four different donors $(n=4)$. (D) PBMCs were incubated with CADA (10 $\mu \mathrm{M})$ or DMSO for 3 days, and subsequently analyzed for cell surface receptors $\mathrm{CD} 3, \mathrm{CD} 4, \mathrm{CD} 8$ and TCR $\alpha / \beta$. Bar diagrams are showing the MFI of the indicated receptor on gated $\mathrm{CD} 4^{+}$or $\mathrm{CD} 8^{+}$subpopulations, with $\mathrm{DMSO}$ in white and CADA in red. Welch's corrected t-tests were performed to compare CADA to DMSO with ${ }^{*} p<0.05$. Values represent mean \pm SD of two different donors $(n=2)$. (E) PBMCs were stimulated with PHA for 3 days and were subsequently exposed to CADA (10 $\mu \mathrm{M})$ or DMSO for another 2 days. Dot plot represents cell surface expression of CD3 and CD4, with DMSO as black dots and with CADA as red overlay. Do note that the CADA-treated cells have similar CD3 expression levels as DMSO, but reduced CD4 levels (see difference in black and red population in upper right quadrant). See also Supplementary Figure 3. 


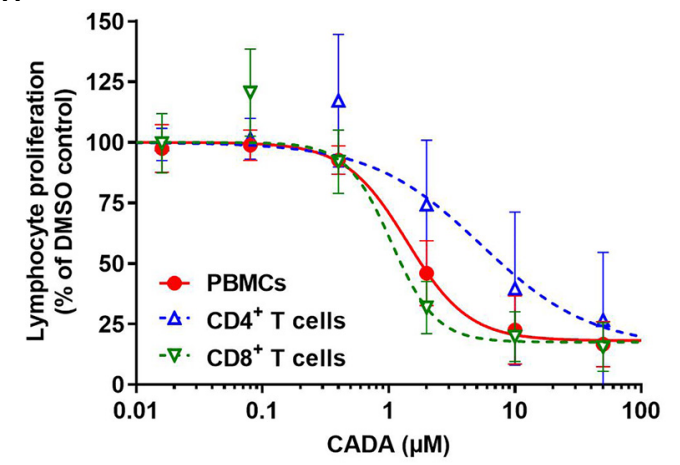

C

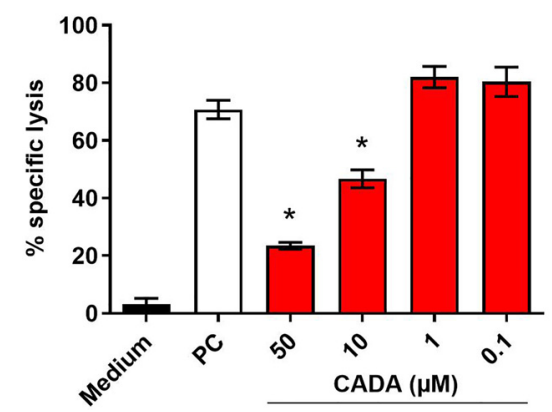

B

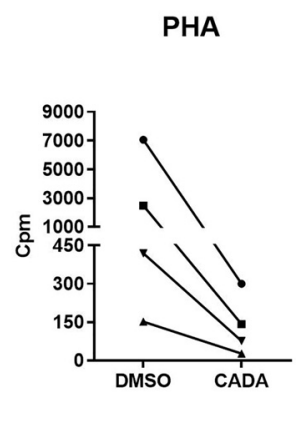

CD3/CD28

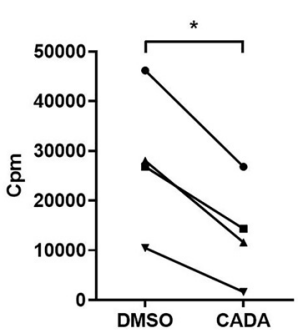

FIGURE 3 | CADA dose-dependently inhibits CD8 ${ }^{+}$T cell proliferation and cytotoxic T cell function. (A) PBMCs (red), purified CD4 ${ }^{+} \mathrm{T}$ cells (blue) or purified CD8 ${ }^{+} \mathrm{T}$ cells (green) were co-cultured with mitomycin C inactivated RPMl1788 cells in the presence of different doses of CADA. At day 5, [ $\left.{ }^{3} \mathrm{H}\right]$-thymidine was added and proliferation response was measured by detecting counts per minute (cpm) 18h later. Lymphocyte proliferation is given as percentage of the corresponding DMSO control (mean \pm SD of six different donors; $n=6$ ). (B) Purified CD8 ${ }^{+}$T cells were pre-incubated with CADA $(10 \mu \mathrm{M})$ or DMSO during 3 days, after which they were activated by PHA or CD3/CD28 beads. At $24 \mathrm{~h}$ post activation, $\left[{ }^{3} \mathrm{H}\right]$-thymidine was added and proliferation response was measured by detecting cpm $20 \mathrm{~h}$ later. Graphs show intra-donor treatment effect on the proliferation response (each donor is indicated separately). A paired t-test was performed to compare CADA to DMSO with ${ }^{*} \mathrm{p}<0.05 ; \mathrm{n}=4$. (C) PBMCs were cultured in medium alone (black) or were co-cultured with inactivated RPMl1788 cells in the absence (white) or presence (red) of increasing doses of CADA during 6 days. Next, PBMCs were exposed to ${ }^{51} \mathrm{Cr}$-loaded RPMl1788 cells for 4h, after which supernatant was collected and ${ }^{51} \mathrm{Cr}$ release was quantified. To measure spontaneous and maximum release of ${ }^{51} \mathrm{Cr}$, medium or saponin was added to the ${ }^{51} \mathrm{Cr}$-loaded RPMl1788 cells, respectively. The mean percentage of specific lysis was calculated by using the following formula: \% specific lysis = (experimental release - spontaneous release)/(maximum release - spontaneous release) $\times 100$. A t-test was performed to compare CADA to DMSO with ${ }^{*} \mathrm{p}<0.05$. Bars represent mean $\pm \mathrm{SD}$ of 4 technical replicates of one donor.

MLR samples, there was a tendency of reduced cytokine release after CADA treatment for IL-9, IL-10, IL-17A, IL-21 and IL-22, that reached statistical significance for IL-21 (Supplementary Figure 4). In contrast, the secretion of IL-23, IL-27 and IL-31 was unaffected by CADA, indicating that there is no direct inhibitory effect of CADA on (signal peptide-dependent) cytokine secretion in general.

\section{CADA Treatment Results in Decreased CD25 Upregulation and Reduced Intracellular PSTAT5 and CTPS1 Levels in Activated PBMCs}

As previous analysis demonstrated reduced IL-2 cytokine release from CADA-treated activated PBMCs, we next focused on the IL-2/IL-2R axis. Expression of the activation marker CD25 (also known as the IL-2 receptor $\alpha$-chain) was determined on both $\mathrm{CD}^{+} \mathrm{T}$ cells and $\mathrm{CD}^{+} \mathrm{T}$ cells (Figure 5A and Supplementary
Figure 5A). Without activation stimuli, very low levels of CD25 were measured, however, CD25 expression was strongly induced starting at $1 \mathrm{~d}$ post $\mathrm{CD} 3 / \mathrm{CD} 28$ beads-activation, reaching a peak around day 2 to 3 (Figure 5A). Comparable data were obtained with PHA activation (Supplementary Figure 5A). CADA preincubation had no effect on basal CD25 levels (Supplementary Figure 5B; d0), nor on the early upregulation of CD25 at $4 \mathrm{~h}$ and 1d post activation (Supplementary Figure 5C and Figure 5A), whereas CD4 expression was clearly reduced in these CADA exposed cells. However, at later time points, CADA inhibited CD25 upregulation significantly in each $\mathrm{T}$ cell subset and in both activation models ( $\mathrm{p}<0.05$; paired t-test). Though, at day 4 post PHA-activation the CD25 expression already declined in most control samples, whereas it stabilized in CADA-treated cells (Supplementary Figures 5A, B). In accordance with cell surface expression of CD25, the level of soluble CD25 (sCD25) in the supernatant of stimulated cells was also reduced by CADA 


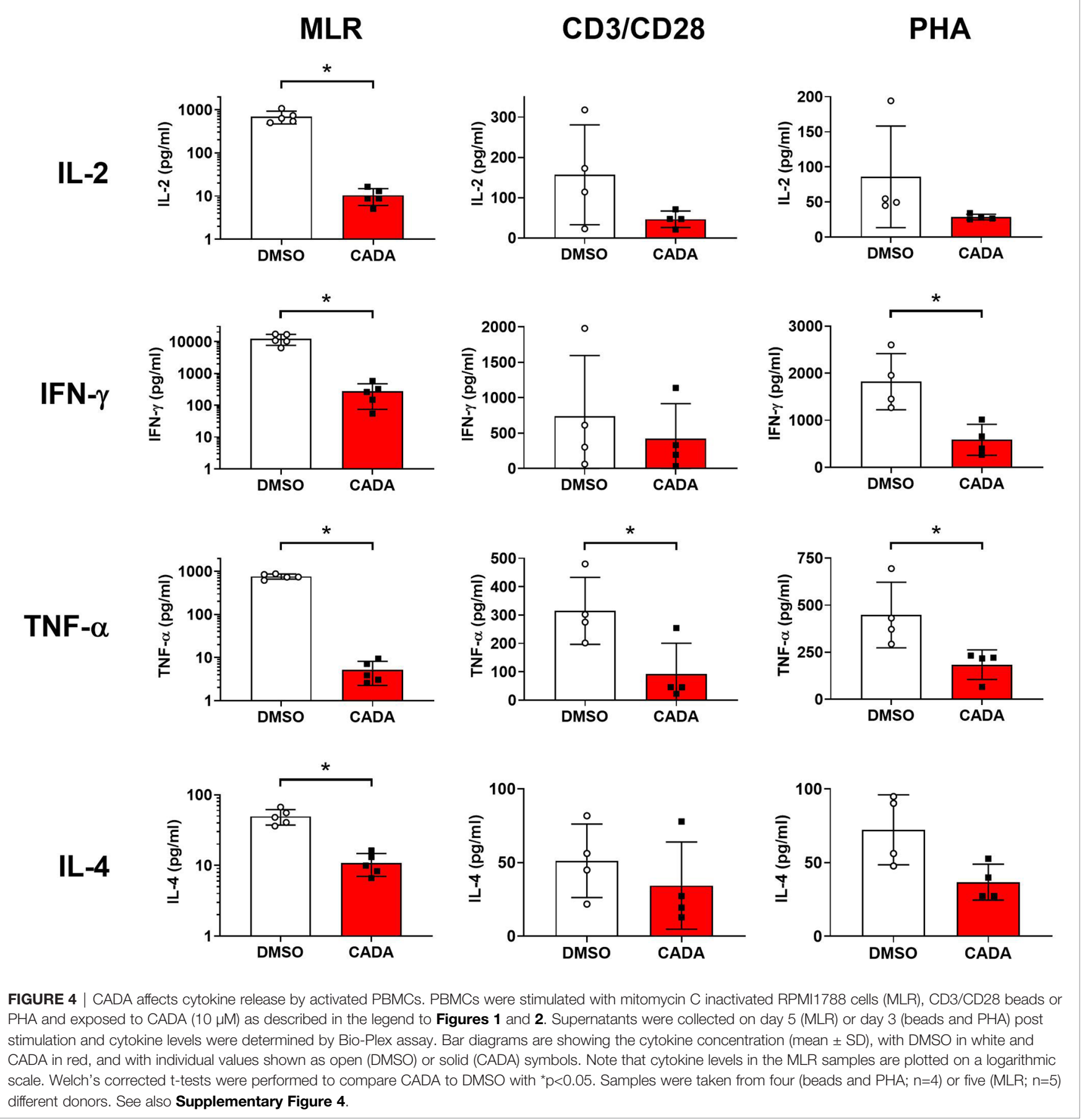

treatment (Supplementary Figure 5D), which was significant for the PHA-stimulated samples that were collected at day 4 .

Transcription of CD25 is enhanced by IL-2 receptor signaling, including activation by phosphorylation of signal transducer and activator of transcription 5 (STAT5). Next, levels of intracellular pSTAT5 and cell surface CD25 were measured simultaneously in PBMCs that were left unstimulated or that were activated by CD3/CD28 beads and
PHA. Half of the samples were given an extra boost with exogenous IL-2. As shown in Figure 5B, most potent induction of CD25 expression in total PBMCs was obtained by PHA stimulation rather than by use of CD3/CD28 beads measured at day 2 post activation. This CD25 upregulation, in the absence or presence of exogenous IL-2, was significantly suppressed by CADA ( $\mathrm{p}=0.001$ and 0.007 , respectively; $\mathrm{t}$-test). Activation with CD3/CD28 beads, in combination with 

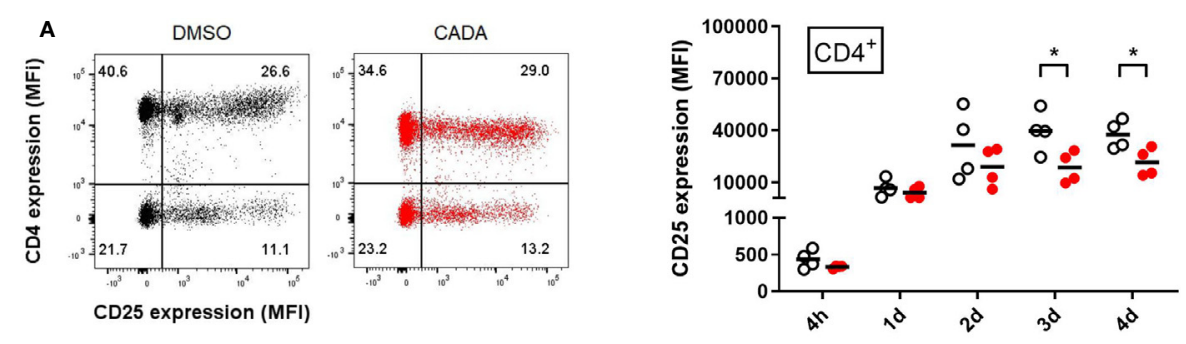

B

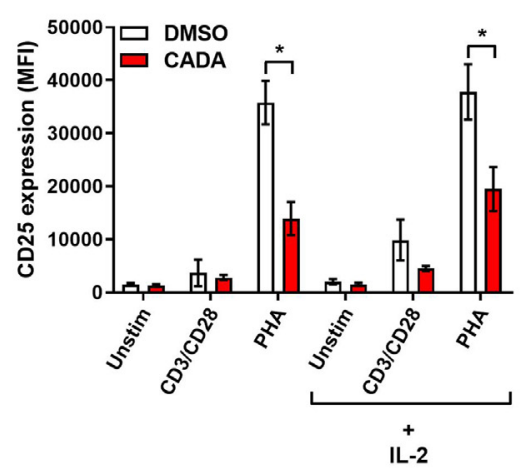

C

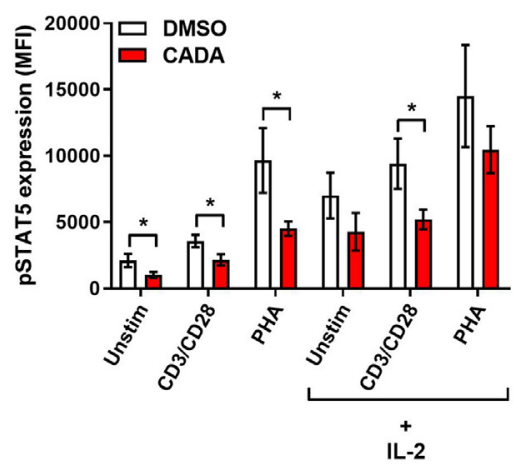

D
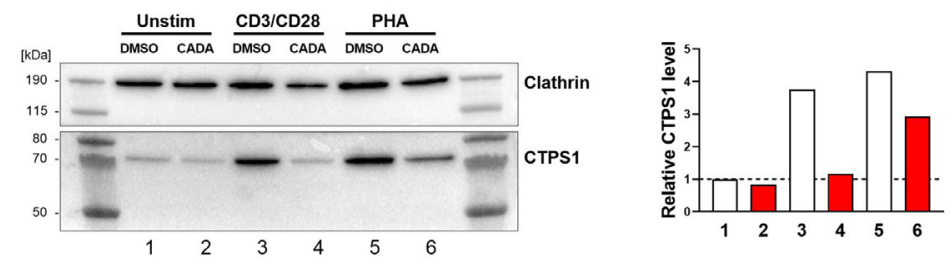

E

$\mathbf{F}$
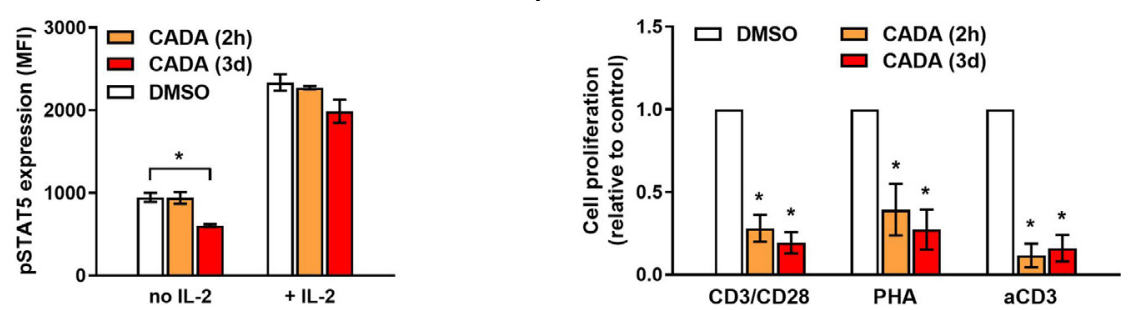

FIGURE 5 | CADA treatment results in decreased CD25 upregulation and reduced intracellular pSTAT5 and CTPS1 levels in activated PBMCs. (A) PBMCs were pre-incubated with CADA $(10 \mu \mathrm{M})$ or DMSO for 3 days, after which they were activated with CD3/CD28 beads. Cellular surface CD25 expression was measured on gated $\mathrm{CD} 4^{+} \mathrm{T}$ cells by flow cytometry at $4 \mathrm{~h}, 1 \mathrm{~d}, 2 \mathrm{~d}, 3 \mathrm{~d}$ or $4 \mathrm{~d}$ post activation. Representative dot plots show CD25/CD4 double staining at $1 \mathrm{~d}$ post activation (for comparison, a dot plot at $4 \mathrm{~h}$ is presented in Supplementary Figure 5C). Graph shows individual MFI values of CD25 expression (acquired from at least 5,000 cells per donor) from different donors with DMSO-treated cells as open symbols and CADA-treated cells as solid red dots. A paired t-test was performed to compare CADA to DMSO with ${ }^{*} p<0.05$. Horizontal lines indicate the mean values of 4 different donors $(n=4)$. (B-D) PBMCs were pre-incubated with CADA or DMSO for 3 days, after which they were left unstimulated or were activated with CD3/CD28 beads or PHA. (B, C) At day 2, half of the samples were boosted with IL-2. Cell surface CD25 receptor (B) and intracellular PSTAT5 (C) expression were simultaneously measured by flow cytometry. Bar diagrams are showing the MFI values for CD25 and pSTAT5 (mean \pm SD). Multiple t-tests were performed to compare CADA (red bars) to DMSO (white bars) for each condition with ${ }^{*} \mathrm{p}<0.05$ and with HolmSidak method as correction for multiple comparison. Data were collected from four different donors $(n=4)$. (D) At day 2 post activation, cells were lysed and CTPS1 expression was detected by western blotting. Clathrin was used as protein loading control. Graph shows quantification of protein bands, normalized to the clathrin internal control. Normalized CTPS1 level of unstimulated DMSO control was set as 1. (E) PBMCs were pre-incubated with CADA or DMSO for 2 hours (2h) or for 3 days (3d), and subsequently left unstimulated (no IL-2) or boosted with exogenous IL-2 (+ IL-2). After 15 minutes, intracellular pSTAT5 expression was measured by flow cytometry. Bar diagrams are showing the MFI for PSTAT5 (acquired from at least 5,000 cells per donor), with DMSO in white and CADA in orange or red. Welch's corrected t-tests were performed to compare CADA to DMSO with ${ }^{*} p<0.05$. Values represent mean \pm SD of two different donors $(n=2)$. (F) PBMCs were pre-incubated with CADA or DMSO for 2 hours (2h) or for 3 days (3d), and subsequently activated with CD3/CD28 beads, PHA or anti-CD3 antibodies. At 24h post activation, $\left[{ }^{3} \mathrm{H}\right]$-thymidine was added and proliferation response was measured by detecting $\mathrm{cpm} 18 \mathrm{~h}$ later. Lymphocyte proliferation was calculated as percentage of DMSO control. Bar diagrams are showing the relative cell proliferation, with DMSO in white and CADA in orange or red. Welch's corrected t-tests were performed to compare CADA to DMSO with ${ }^{*} p<0.05$. Values represent mean \pm SD of three different donors $(n=3)$. See also Supplementary Figure 5. 
exogenous IL-2 also resulted in detectable levels of CD25 (Figure 5B). Intracellular pSTAT5 levels were clearly elevated after activation, with the largest increase for the PHA-stimulated samples (Figure 5C and Supplementary Figure 5E). Administration of additional IL-2 led to a general increase in pSTAT5 in all tested conditions. As summarized in Figure 5C, CADA clearly reduced the levels of pSTAT5 (as compared to the corresponding DMSO control), that reached significance for the samples without IL-2 boost.

In addition, the expression level of cytidine triphosphate synthase 1 (CTPS1) - an important immune checkpoint in $\mathrm{T}$ cell responses - was determined as its transcription is induced by activated STAT5. CTPS1 is highly upregulated after stimulation and it has been reported to be crucial for proliferation of $\mathrm{T}$ and $\mathrm{B}$ cells after activation (27). As shown in Figure 5D, in unstimulated cells low basal levels of CTPS1 were detected by means of western blot, while enhanced expression was observed after activation by CD3/CD28 beads and PHA. CADA clearly attenuated the activation-induced CTPS1 upregulation (Figure 5D), which is in line with the effect of CADA on the upstream pSTAT5 levels (Figure 5C).

To explore if there is a direct inhibitory effect of CADA on STAT5 phosphorylation (or upstream signaling molecules), we assessed the impact of CADA on pSTAT5 levels induced by direct IL-2 activation, independently of co-stimulatory receptors such as CD28. As shown in Figure 5E, short (2h) pre-treatment of the cells with CADA before administration of IL-2 did not alter the increase in phosphorylated STAT5, whereas in cells exposed to CADA for 3 days (that obtained down-modulated cell surface CD4 levels) there is a tendency of (slightly) reduced pSTAT5. Of note, pre-treatment of the cells for $2 \mathrm{~h}$ before activation with $\mathrm{CD} 3 / \mathrm{CD} 28$ beads or PHA was equally sufficient to inhibit $\mathrm{T}$ cell activation as the long (3d) CADA pre-treatment (Figure 5F), indicating that this short exposure of the cells to the drug is sufficient for CADA to reach its cellular target(s). These data demonstrate that CADA has no direct effect on pSTAT5, and that the reduced levels of phosphorylated STAT5 seen in CADA treated cells is rather a secondary effect from attenuated cell activation.

Interestingly, stimulation of cells with anti-CD3 antibodies only was significantly inhibited by CADA (Figure 5F). In fact, the inhibitory effect of CADA on the proliferation of PBMCs activated by anti-CD3 was slightly more successful as compared to its inhibition of the stimulation by CD3/CD28 beads or PHA (Figure 5F).

\section{CADA Strongly Suppresses the Upregulation of the Co-Stimulatory Molecule 4-1BB in Activated PBMCs}

In addition to CD25, we evaluated the expression level of CD28, a key co-stimulatory receptor in $\mathrm{T}$ cell activation. Cell surface CD28 expression levels started to rise at day 2 post activation (Supplementary Figure 6). Treatment with CADA had no profound effect on the early upregulation of CD28 (Supplementary Figures 6A, B), but resulted in a significant reduction in $\mathrm{CD} 28$ levels of $\mathrm{CD}^{+}$and $\mathrm{CD}^{+} \mathrm{T}$ cells, both after CD3/CD28 and PHA stimulation at later time points (Figure 6A and Supplementary Figure 6). By day 4 post activation, CD28 expression levels generally increased also in the CADA-exposed samples (Supplementary Figures 6B, C), indicating that CADAtreatment resulted in a delayed upregulation of CD28 rather than a complete and sustained suppression of this co-receptor.

Cell surface levels of the human co-stimulatory receptors tumor necrosis factor receptor superfamily [TNFRSF] member 4 (TNFRSF4), also named OX40 or CD134, and 4-1BB (also named CD137 or TNFRSF9) were assessed after activation by CD3/CD28 beads or PHA. OX40 is transiently expressed after antigen recognition primarily on activated $\mathrm{CD} 4{ }^{+} \mathrm{T}$ cells found preferentially at the site of inflammation $(28,29)$. Expression of $4-1 \mathrm{BB}$ is highly induced in $\mathrm{CD}^{+} \mathrm{T}$ and NK lymphocytes upon activation via CD3-TCR engagement. It exerts regulatory effects on $\mathrm{T}$ cells mediating activation and persistence of $\mathrm{CD}^{+} \mathrm{T}$ lymphocytes (30-32). As shown in Figure 6A, activation of the control cells evoked a strong but variable upregulation of OX40, with higher elevated levels after stimulation with PHA as compared to $\mathrm{CD} 3 / \mathrm{CD} 28$ beads activation. The suppressive effect of CADA on OX40 upregulation was rather weak in PHA-stimulated cells ( $13 \pm 12 \%$ reduction in MFI), though it was more pronounced ( $51 \pm 19 \%$ reduction in MFI) in the case of CD3/CD28 beads activation. The most striking effect was observed for $4-1 \mathrm{BB}$ expression. In both activation models, an uniform increase in $4-1 \mathrm{BB}$ expression was measured in the DMSO control samples of the different donors (Figure 6B). In sharp contrast, CADA nearly completely blocked the upregulation of $4-1 \mathrm{BB}$ in all samples $(89 \pm 4 \%$ and $79 \pm 3 \%$ reduction in MFI for $\mathrm{CD} 3 / \mathrm{CD} 8$ and $\mathrm{PHA}$, respectively), which was highly significant ( $\mathrm{p}=0.0025$ and 0.0011 , respectively; paired t-test). Further analysis of 4 -1BB kinetics indicated that the transient expression of $4-1 \mathrm{BB}$ in $\mathrm{CD}^{+} \mathrm{T}$ cells starts as early as $12 \mathrm{~h}$ post stimulation and lasts for approximately $36 \mathrm{~h}$, whereas its expression in $\mathrm{CD}^{+} \mathrm{T}$ cells peaks around $48 \mathrm{~h}$ post stimulation (Figure 6C). Importantly, CADA completely abrogated the 4-1BB upregulation in both $\mathrm{CD}^{+}$and $\mathrm{CD}^{+} \mathrm{T}$ cells activated by $\mathrm{CD} 3 / \mathrm{CD} 28$ beads or PHA (Figure 6C). Also, in PBMCs activated by anti-CD3 antibodies only, a substantial upregulation of $4-1 \mathrm{BB}$ expression was obtained in the DMSO samples, whereas a short CADA pre-treatment of the cells was sufficient to keep the cells 4-1BB negative (Figure 6D).

\section{CADA Dose-Dependently and Reversibly Suppresses the Cellular Expression of 4-1BB in Transfected Cells}

Previous data suggest that CADA might have a direct inhibitory effect on the receptor biogenesis of $4-1 \mathrm{BB}$, similar to that of CD4. To address this, we cloned $4-1 \mathrm{BB}$ in a vector to express the receptor fused to turbo green fluorescent protein (tGFP) in a P2A-RFP context (Figure 7A), as described previously (23). As a positive control, hCD4 was included. The same reporter vector was also used to express other co-stimulatory receptors from the same genetic background. Protein expression was determined by tGFP fluorescence, while the amount of cytosolic RFP served as a control for transfection and expression efficiency. As shown in Figure 7B, CADA dose-dependently inhibited 4-1BB expression 
A

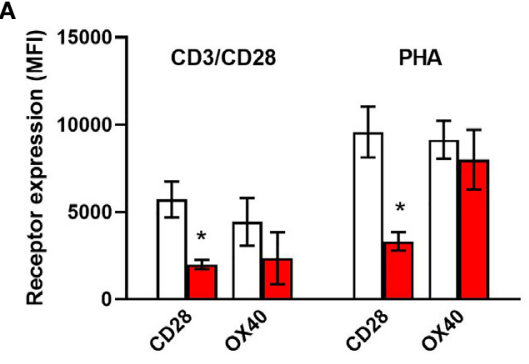

C
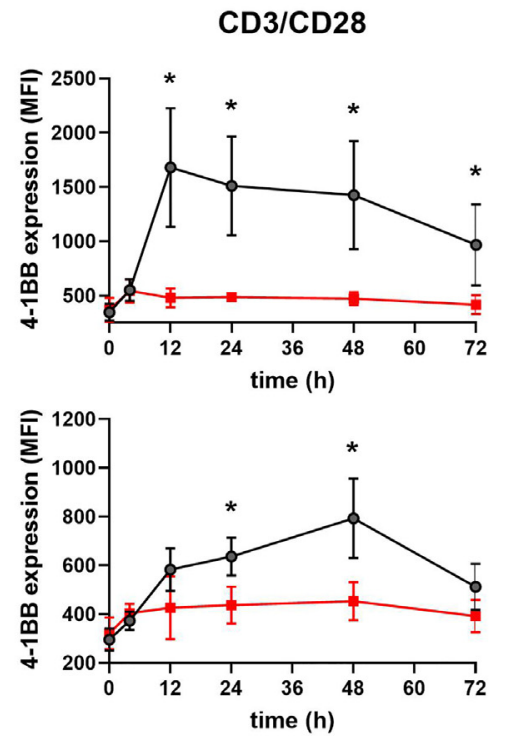

D

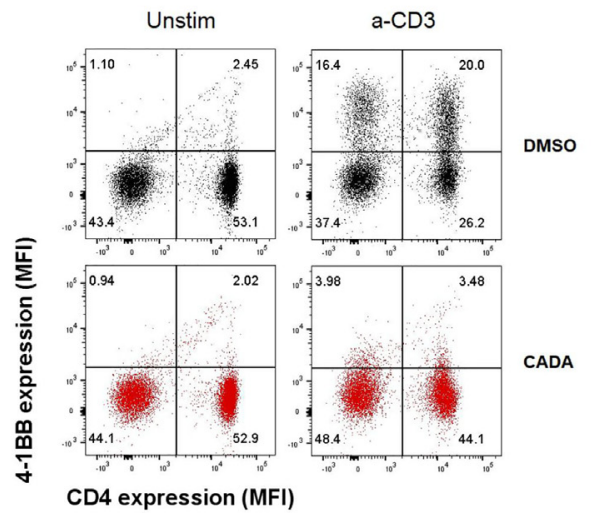

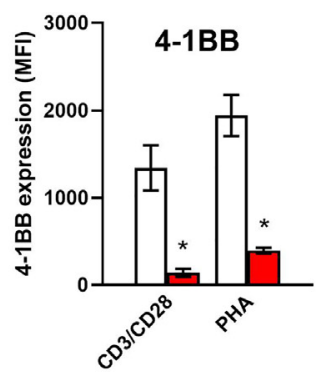

PHA
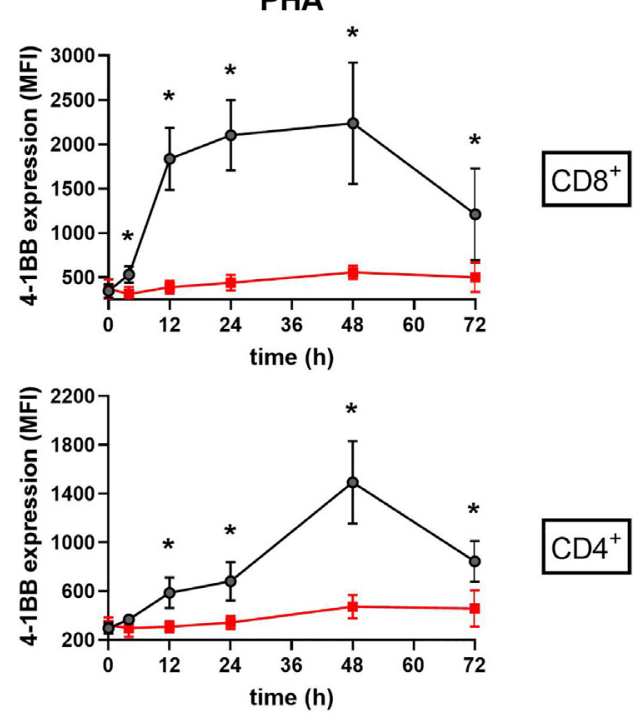

FIGURE 6 | CADA strongly suppresses the upregulation of the co-stimulatory molecule 4-1BB in activated PBMCs. (A, B) PBMCs were pre-incubated with CADA $(10 \mu \mathrm{M})$ or DMSO for 3 days, after which they were activated by CD3/CD28 beads or PHA. Cell surface CD28 expression was measured on gated CD4 ${ }^{+} \mathrm{T}$ cells by flow cytometry on d3 post activation. Cell surface expression of OX40 and 4-1BB was measured on total PBMCs by flow cytometry on d2 post activation. Bar diagrams are showing the MFI for the indicated receptor, with DMSO in white and CADA in red. Paired t-tests were performed to compare CADA to DMSO with ${ }^{*} \mathrm{p}<0.05$. Values represent mean $\pm \mathrm{SD}$ of four different donors $(\mathrm{n}=4)$. (C) PBMCs were pre-incubated with CADA (10 $\mu$ M) or DMSO for 3 days, after which they were activated by CD3/CD28 beads or PHA. Cell surface 4-1BB expression was measured on gated CD4 ${ }^{+}$and CD8 ${ }^{+} \mathrm{T}$ cells by flow cytometry on the indicated time points post activation. Multiple t-tests were performed to compare CADA to DMSO for each condition with * $\mathrm{p}<0.05$ and with Holm-Sidak method as correction for multiple comparison. Curves are showing mean values \pm SD of six different donors ( $n=6)$. (D) PBMCs were pre-incubated with CADA (10 $\mu$ M) or DMSO for 2 hours, and subsequently activated by anti-CD3 antibodies only. Cell surface CD4 and 4-1BB expression was measured by flow cytometry at 24h post activation. Representative dot plots for CD4 and 4-1 BB double staining are shown for unstimulated and stimulated cells. Do note that this short CADA-treatment has neglectible effect on the CD4 expression in unstimulated cells (see lower right quadrants), but blocks the expression of 4-1BB in activated cells, both in CD4 negative (upper left quadrant) and CD4 positive cells (upper right quadrant). See also Supplementary Figure 6. 
A

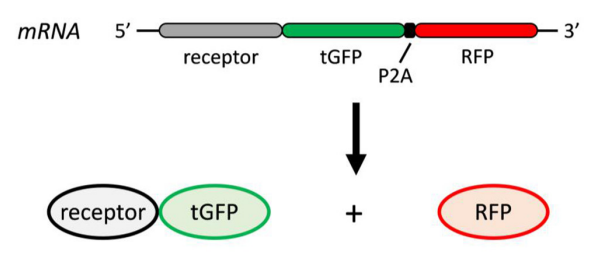

C

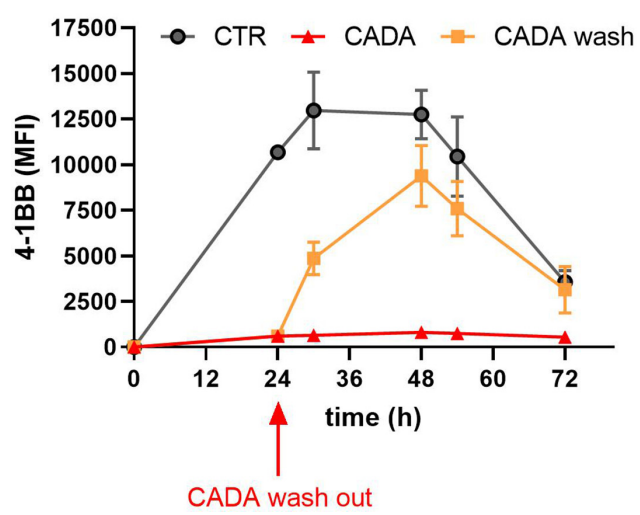

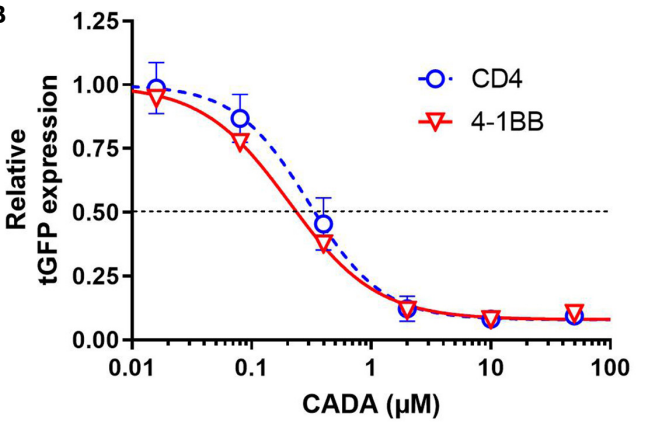

D

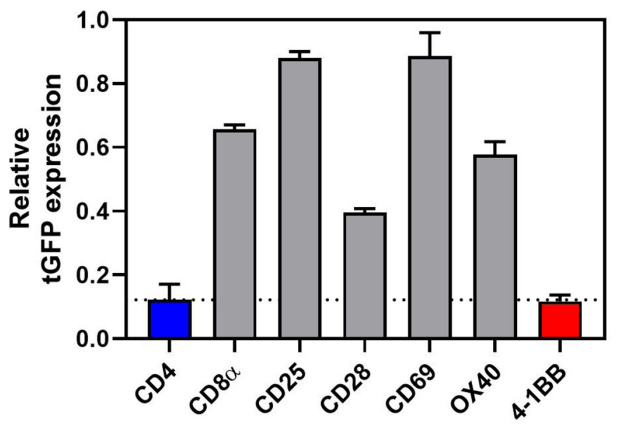

FIGURE 7 | CADA dose-dependently and reversibly suppresses the cellular expression of 4-1BB in HEK293T cells. (A) Schematic representation of the expected mRNA and protein products of the tGFP-2A-RFP construct. (B-D) HEK293T cells were transiently transfected with the different constructs. CADA was added 6h post transfection and cellular expression of each receptor was determined by measuring tGFP levels by flow cytometry. (B) Four parameter dose-response curves for CADA of human CD4tGFP-2A-RFP and human 4-1BBtGFP-2A-RFP. Cells were collected 24h post transfection and tGFP was measured by flow cytometry. Receptor levels in CADA-treated samples are normalized to the corresponding DMSO control. Curves are showing mean values \pm SD of at least 3 independent experiments $(n \geq 3)$. (C) Cells were transfected with 4-1BBtGFP-2A-RFP and given DMSO (CTR) or treated with CADA for 72h. In parallel, CADA-treatment was terminated after 24h (CADA wash). These cells were washed profoundly and given control medium for the duration of the experiment. At the indicated time points, cells were collected and tGFP was measured by flow cytometry. At each time point, the average MFI of tGFP (acquired from at least 10,000 cells per experiment) is shown. Of note is that the SD of the CADA samples (red curve) is too small to be visible on the graph. Curves are representing mean values \pm SD of 2 independent experiments $(n=2)$. (D) Cells were collected $24 \mathrm{~h}$ post transfection and tGFP was measured by flow cytometry. Bar diagrams are showing the protein levels in CADAtreated samples, normalized to the corresponding DMSO control (set as 1.0). Values represent mean \pm SD of at least three independent experiments ( $\mathrm{n} \geq 3$ ). See also Supplementary Figure 7.

in transfected HEK293T cells. This direct down-modulatory effect of CADA on 4-1BB was almost complete and similar to its effect on hCD4 ( $\mathrm{IC}_{50}$ of $0.24 \mu \mathrm{M}$ and $0.30 \mu \mathrm{M}$, respectively), demonstrating that $4-\mathrm{B} 11$ is a valuable substrate of CADA (Figure 7B). The down-modulating effect of CADA on 4-1BB is reversible in nature, as evidenced by the re-expression of $4-1 \mathrm{BB}$ after wash-out of CADA (Figure 7C), an effect that is observed for hCD4 as well (Supplementary Figure 7A) as reported earlier $(21,22)$. As summarized in Figure $7 \mathbf{D}$, in addition to the potent inhibition of hCD4 and 4-1BB expression, CADA also partially reduced cellular levels of other co-stimulatory receptors in transfected cells. Whereas the level of CD8 and OX40 in CADA treated cells was reduced by approximately $40 \%$, the effect of CADA on the expression of CD25 and CD69 was only minor. A reduction of $60 \%$ was measured in the expression of CD28 in CADA exposed cells (Figure 7D and Supplementary Figure 7B).

\section{CADA Inhibits 4-1BB Protein Biogenesis in a Signal Peptide-Dependent Way by Blocking the Co-Translational Translocation of 4-1BB Into the Endoplasmic Reticulum}

Finally, to explore the molecular mechanism by which CADA inhibits $4-1 \mathrm{BB}$ protein expression, we addressed if the cleavable signal peptide (SP) of the $4-1 \mathrm{BB}$ pre-protein is the susceptible region for CADA activity, similar to what we have described for hCD4 $(22,23)$. Thus, constructs were generated as depicted in Figure 8A. Briefly, starting from the CADA-resistant mouse CD4 (mCD4) protein sequence, we exchanged the N-terminal region containing the SP and the first 7 amino acids of the mature protein of mCD4 with that of hCD4 or $4-1 \mathrm{BB}$, respectively. As previously demonstrated (22), CADA did not affect the expression of wild-type mouse CD4 when transfected 


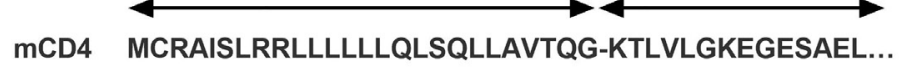

hmCD4 MNRGVPFRHLLLVLQLALLPAATQG-KKVVLGKEGESAEL...

4-1BBmCD4 $\frac{\text { MGNSCYNIVATLLLVLNFERTRS-LQDPCSNEGESAEL... }}{\text { SP }}$

Murine CD4 sequence Human CD4 sequence Human 4-1BB sequence
B

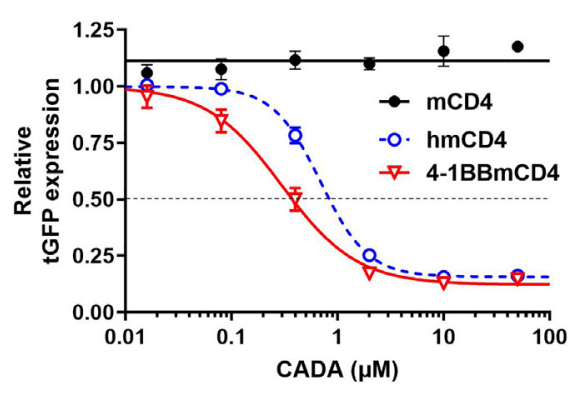

C

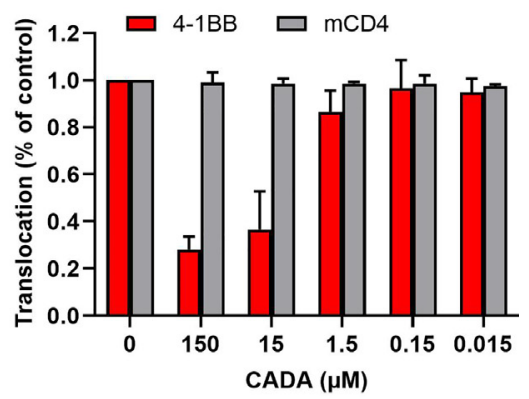

D

$+\quad+\quad+\quad+\quad+$ membranes

$\begin{array}{lllllllll}0 & 0 & 150 & 15 & 1.5 & 0.15 & 0.015 & \mathrm{CADA}(\mu \mathrm{M})\end{array}$

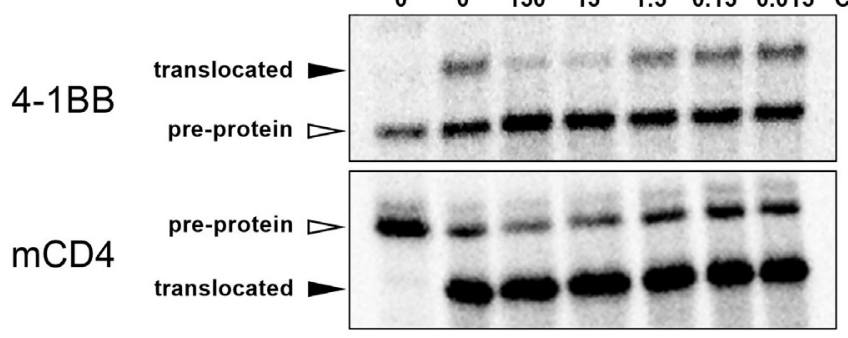

$\mathbf{E}$

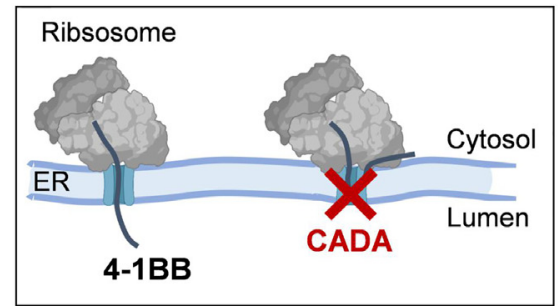

FIGURE 8 | CADA inhibits 4-1BB protein biogenesis in a signal peptide-dependent way by blocking the co-translational translocation of 4-1BB into the endoplasmic reticulum. (A) Schematic representation of the constructs used. In the hmCD4 construct, the signal peptide (SP) and the first 7 amino acids of the mature protein are of human CD4 (indicated in blue), whereas in the 4-1BBmCD4 construct the SP and the 7 AA of mature 4-1BB (indicated in red) are fused to mouse CD4. During pre-protein biogenesis, the SP is cleaved off from the mature protein. The constructs express the mature protein of mouse CD4 that is C-terminally fused to tGFP as shown in Figure 7A. (B) HEK293T cells were transfected with the mCD4 (black; n=3), hmCD4 (blue; n=3) and 4-1BBmCD4 (red; n=4) constructs. CADA was added $6 \mathrm{~h}$ post transfection and expression of tGFP was measured by flow cytometry $24 \mathrm{~h}$ post transfection. The tGFP expression is given as percentage of DMSO control (mean $\pm \mathrm{SD}$ ). IC $\mathrm{C}_{50}$ values are $0.84 \mu \mathrm{M}, 0.38 \mu \mathrm{M}$ and $>50 \mu \mathrm{M}$ for hmCD4, 4-1BBmCD4 and mCD4, respectively. (C, D) In vitro translation and translocation of 4-1BB and mCD4 in a radiolabeled cell-free rabbit reticulocyte lysate system. (C) Graph shows the calculated translocation efficiencies. Signal intensities of the pre-protein and translocated protein fraction were used to calculate the translocation efficiency, i.e., translocated fraction/(pre-protein + translocated fraction). Bars show mean \pm SD; $n=2$. (D) Representative autoradiogram of the in vitro translated and translocated wild-type 4-1BB and mCD4 proteins. For mCD4 a truncated form of 250 residues was used without glycosylation sites and transmembrane region. In the presence of membranes, the pre-protein (open arrowhead) of mCD4 is translocated into the ER lumen and the SP is cleaved off, resulting in a faster migrating mature protein (black arrowhead). For wild-type 4-1BB, the SP is cleaved off but the protein is also glycosylated, resulting in a slower migrating mature protein (black arrowhead). (E) Cartoon showing CADA inhibiting the co-translational translocation of 4-1BB protein across the ER membrane. See also Supplementary Figure 8. 
in HEK293T cells (Figure 8B). Expectedly, mCD4 could be fully sensitized to CADA by substituting the mCD4 SP and the first 7 amino acids of the mature $\mathrm{mCD} 4$ protein by the human sequence (hmCD4 construct; Figure 8B), confirming that CADA-sensitivity depends on the presence of a hCD4 SP. Interestingly, expression of mouse $\mathrm{CD} 4$ could also be dosedependently down-modulated by CADA when mCD4 contained the 4-1BB SP and 7 AA of the mature 4-1BB protein (Figure 8B). In fact, 4-1BBmCD4 was slightly more affected by CADA as compared to the hmCD4 chimaera, as evidenced by the $\mathrm{IC}_{50}$ values for receptor down-modulation (0.38 and 0.84 $\mu \mathrm{M}$, respectively).

Signal peptides are critical targeting sequences for secretory and type I integral membrane proteins to guide these proteins to the secretory pathway $(33,34)$. They are involved in the correct targeting of translating ribosomes to the endoplasmic reticulum (ER) membrane, and the subsequent selective translocation of secretory and type I integral membrane proteins across the Sec61 translocon channel in the ER membrane (Supplementary Figure 8A) $(35,36)$. By the use of a cell free in vitro translation/ translocation assay (25), we next evaluated the impact of CADA specifically on the translocation step of $4-1 \mathrm{BB}$ (Supplementary Figure 8B). Transcripts of full length 4-1BB were translated in vitro into a pre-protein of approximately 30 $\mathrm{kDa}$, containing its SP (Figure 8D, top panel). By adding microsomal membranes, representing the ER, combined translation and translocation can occur, resulting in SP-cleaved proteins that are further glycosylated in the ER lumen by the oligosaccharyltransferase (OST) complex (Supplementary Figure 8A). As shown in Figure 8D, wild-type $4-1 \mathrm{BB}$ is efficiently translocated into the lumen of the microsomal membranes, as evidenced by the higher molecular weight band on the gel representing the translocated (thus, glycosylated) 4-1BB species. However, addition of CADA to this translocation mixture strongly reduced the fraction of translocated protein, demonstrating that CADA specifically inhibits the protein translocation step of $4-1 \mathrm{BB}$ (Figure 8C). In contrast, CADA had no effect on the translocation of wild-type truncated mCD4 (without glycosylation sites), as evidenced by the equal amount of faster migrating SP-cleaved species (Figures 8C, D; bottom panel). These data demonstrate that CADA specifically inhibits the co-translational translocation of $4-1 \mathrm{BB}$ across the ER membrane in a signal peptide-dependent manner (Figure 8E).

\section{DISCUSSION}

This study aimed at evaluating the immunosuppressive potential of CADA, a small molecule that blocks hCD4 protein biosynthesis in a SP-dependent way and thereby reduces cell surface hCD4 expression to low basal level. Here, we demonstrated a consistent dose-dependent inhibitory effect of CADA on lymphocyte proliferation in a MLR setting. The inhibition of lymphocyte proliferation by CADA was milder than by the currently used anti-proliferative immunosuppressive agent MMF. Although less potent, CADA has the major advantage that it exerted no cellular toxicity and it was barely cytostatic in vitro, both promising beneficial characteristics of an immunosuppressive drug. In addition, the biological effect of CADA is reversible as evidenced by the quick re-expression of the targeted receptors when treatment was terminated. CADA had little suppressive effect on superantigen-induced activation of $\mathrm{T}$ cells where the stimulation of lymphocytes exceeds physiological levels. This can be explained by the unique binding of superantigens to major histocompatibility complex proteins, which occurs outside the normal peptide-binding groove and thus without intracellular processing (37). The complex ligand so formed has specificity for a particular part of $\mathrm{T}$ cell receptors, $\mathrm{V}$ beta, and by engaging $\mathrm{V}$ beta can stimulate many $\mathrm{T}$ cells. Interactions between superantigen and TCR or MHC are most likely of sufficiently high affinity to obviate the contribution of the CD4 (and/or other co-) receptors in this activation process (38), explaining the lack of a significant suppressive effect of CADA which was expected to be mainly CD4-based. With additional data generated in three different in vitro $\mathrm{T}$ cell activation models (i.e., CD3/CD28 beads, PHA and anti-CD3 Abs), we confirmed that CADA significantly inhibits the proliferation response of stimulated lymphocytes. Although the activation signals in T cells in these models are weakened but not completely blocked by CADA, this partial and temporal suppressive effect of CADA is certainly meaningful. Notably, the supra physiological stimulation of T cells with CD3/CD28 beads or PHA is a condition that is never achieved in a normal in vivo setting where only a small subset of T cells is selectively triggered.

When comparing the active dose ranges of CADA with Clenoliximab in the MLR, we concluded that CADA was more potent than Clenoliximab at down-modulating hCD4 expression and at inhibiting lymphocyte proliferation. Clenoliximab is a nondepleting anti-CD4 monoclonal antibody that directly targets the hCD4 receptor (26). This antibody reached phase II clinical trial for the treatment of rheumatoid arthritis (39). The concentrations of Clenoliximab used in our study were considered adequate to obtain maximum activity, as previously an $\mathrm{IC}_{50}$ of $14.6 \mathrm{ng} / \mathrm{ml}$ Clenoliximab was reported in the MLR (40). However, in our hands Clenoliximab exerted only a partial immunosuppressive effect, but this may be due to different assay characteristics (Reddy et al. used a three-way MLR, whereas we performed a one-way MLR). Either way, the data presented here indicate that the immunosuppressive capacity of CADA in the MLR exceeded that of Clenoliximab. Remarkably, at concentrations of 50,10 and $2 \mu \mathrm{M}$ of CADA similar downmodulation of hCD4 was elicited, whereas the inhibitory effect of CADA on lymphocyte proliferation still increased with higher concentrations (Supplementary Figure 2). This suggested that besides reduction in CD4 expression, other factors may be at play in the total immunosuppressive effect of CADA.

Interestingly, CADA inhibited the proliferation of purified $\mathrm{CD}^{+} \mathrm{T}$ cells to the same extent in the absence of other immune cell types as compared to the proliferation of total PBMCs in the MLR. In addition, the proliferation of purified $\mathrm{CD}^{+} \mathrm{T}$ cells by stimulation with $\mathrm{CD} 3 / \mathrm{CD} 28$ beads or PHA was also clearly 
suppressed by CADA treatment. Moreover, CADA inhibited cytotoxic cell activity in a cell-mediated lympholysis assay. These data demonstrate a direct inhibitory effect of CADA on $\mathrm{CD}^{+}$ $\mathrm{T}$ cell proliferation and function, independently of CD4 receptor expression. This effect cannot solely be attributed to reduced CD8 receptor levels measured in the cytotoxic $\mathrm{T}$ cells, as CADA suppressed CD8 levels only partially. Similar to the function of $\mathrm{CD} 4$ on $\mathrm{CD} 4{ }^{+} \mathrm{T}$ cells, the CD8 receptor enhances the sensitivity of $\mathrm{CD}^{+} \mathrm{T}$ cells to antigens and is required for the formation of a stable complex between major histocompatibility complex class I and the $\mathrm{T}$ cell receptor (41). However, the nearly complete inhibition of $4-1 \mathrm{BB}$ upregulation in $\mathrm{CD}^{+}$cells is most likely one of the main raisons for the strong non-CD4 dependent immunosuppression of CADA in the $\mathrm{CD}^{+} \mathrm{T}$ cell population. Indeed, a clear role of 4-1BB in augmenting $\mathrm{T}$ cell cytotoxicity and $\mathrm{CD}^{+} \mathrm{T}$ cell survival has been reported in literature (30-32). The surface glycoprotein $4-1 \mathrm{BB}$ is a member of the TNFR family whose expression is highly induced in $\mathrm{CD}^{+} \mathrm{T}$ and NK lymphocytes upon activation via CD3-TCR engagement. It functions as an inducible co-stimulatory molecule that can exert regulatory effects on $\mathrm{T}$ cells mediating activation and persistence of cytotoxic T lymphocytes independently of CD28 stimulation (30, 42-46). Our data showing significant $4-1 \mathrm{BB}$ expression in PBMCs activated by anti-CD3 Abs only are certainly in line with these reports. Furthermore, the strong inhibitory effect of CADA on this anti-CD3 induced 4-1BB expression support our hypothesis that early $4-1 \mathrm{BB}$ suppression is a main contributor to CADA's immunosuppressive activity. The finding that 4-1BB-mediated co-stimulation is critical for $\mathrm{CD}^{+} \mathrm{T}$ cell responses is further underlined in $4-1 \mathrm{BB}$ deficient mice in which decreased IFN- $\gamma$ production and cytolytic $\mathrm{CD} 8^{+} \mathrm{T}$ cell effector function were observed (47). In addition, 4-1BB deficiency in patients resulted in defective $\mathrm{CD}^{+} \mathrm{T}$ cell activation and cytotoxicity against virusinfected B cells (48).

From our molecular biology data, we concluded that $4-1 \mathrm{BB}$ is an additional substrate of CADA in the context of cotranslational protein translocation inhibition across the ER membrane during early protein biogenesis. This process involves the SP of the pre-protein for inserting into the translocon channel of the ER and correct routing along the secretory pathway (33-36). Undoubtedly, target specificity of CADA remains an important question to address. Although originally assumed that hCD4 was the sole target of CADA (22), a recent proteomic study indicated sortilin as a secondary substrate of CADA but with reduced sensitivity to the drug (49). Importantly, in an additional proteomics analysis of SUPT1 cells (which is still ongoing), only three hits out of more than 3000 quantified integral membrane proteins with cleavable signal peptides could be identified as significantly affected by CADA, but all with weaker sensitivity as compared to hCD4, indicating that CADA exerts high substrate selectivity. Also, in our current study it is clear that CADA has not a general inhibitory effect on protein translocation of the total integral membrane fraction as evidenced by CD25 and CD69 (whose expression in transfected cells was unaffected by CADA), nor on the secretome as evidenced by several cytokines such as IL-23, IL-27 and IL-31 whose secretion from activated cells was unaltered under CADA pressure. From our comparative analysis in transfected cells we can now conclude that $4-1 \mathrm{BB}$ is the most sensitive substrate of CADA identified so far, making it an ideal target for further mechanistic studies. A recent study on SP mutants of hCD4 showed that sensitivity to CADA partially depends on the functionality of the SP (determined by hydrophobicity and charges) and on the presence of some critical residues (23). Although hCD4 and 4-1BB have both unique SPs in terms of primary sequence (Figure 8A), their SP's hydrophobic core (LLLVLQ/N) shows some similarity. By comparison of both CADA substrates we aim to get a better understanding of how a small molecule can exert such a high substrate selectivity for ER translocation inhibition and hope to ultimately design novel ER translocation inhibitors for therapeutic use.

The upregulation of several immunologically relevant receptors after $\mathrm{T}$ cell stimulation was shown to be affected by CADA. To distinguish between reduced expression level because of a general immunosuppression by CADA and a direct inhibition of protein translocation and subsequent receptor expression, we evaluated the expression efficiency of each receptor independently in transfected cells. Unaffected by CADA directly, the expression of late activation marker CD25 - also known as IL-2 receptor $\alpha$ chain - was significantly reduced and somewhat delayed by CADA after activation with CD3/CD28 beads and PHA at later time points post stimulation. Thus, the CD25 expression level in CADA-exposed activated $\mathrm{T}$ cells is a relevant measurement of the degree of actual $\mathrm{T}$ cell activation. This can also explain the higher variation in CD25 expression level between the different CADAtreated donors (Supplementary Figure 5A) as compared to hCD4 (Figure 2B). Expectedly, we also observed a decreased amount of sCD25 in the supernatant of activated lymphocytes. sCD25 is a sensitive marker for activation of the immune system and it can also be used as a potential marker for subclinical macrophage activation syndrome in patients with active systemic onset juvenile idiopathic arthritis (50). CD25 expression is massively upregulated after $\mathrm{T}$ cell activation involving $\mathrm{T}$ cell receptor and IL-2 receptor signaling pathways (51). In the IL-2 receptor signaling pathway, activation of STAT5 by phosphorylation is crucial to enhance CD25 expression. Furthermore, cytidine triphosphate synthase 1 (CTPS1) transcription is induced by activated STAT5, and as an enzyme in the de novo synthesis of cytidine triphosphate, CTPS1 is crucial for proliferation of activated $\mathrm{T}$ and $\mathrm{B}$ cells (27). Its expression is rapidly and strongly upregulated following $\mathrm{T}$ cell activation. CTPS1 plays a predominant role in selected immune cell populations - e.g. CTPS1-deficient patients present with a lifethreatening immunodeficiency - making CTPS1 an interesting target for the development of highly selective immunomodulatory drugs. CADA-treatment not only resulted in reduced CD25 and pSTAT5, but also in reduced down-stream CTPS1 expression. However, the reduced pSTAT5 and CTPS1 levels seem to be secondary effects of CADA's immunosuppressive activity (e.g., through lower IL-2 production), given that STAT5 phosphorylation triggered by exogenous IL-2 only was not affected by CADA. This suggests that a direct effect of CADA on interfering with cytosolic signaling molecules upstream of 
STAT5, such as JAK1 or JAK3, is most unlikely. In addition, an earlier proteomics study on T cells showed no effect of CADA on several CD4/TCR related signaling molecules, such as p56 lck, ZAP-70 and STAT1 (49). Furthermore, as CADA acts on the cotranslational translocation of its target proteins, it is expected that CADA substrates belong to the proteome that is routed to the secretory pathway and carry cleavable signal peptides (such as cell surface receptors and secreted proteins), rather than cytosolic proteins. In this context it would be interesting to further explore the effect of CADA on different co-stimulatory receptors and/or secreted cytokines that are rapidly expressed after stimulation of the cells via CD3/TCR only.
A major co-stimulatory receptor in T cell activation is CD28. Given that CADA had no significant effect on CD28 levels at the early time points post stimulation, the immunosuppressive effect of CADA seen on PBMCs stimulated with CD3/CD28 beads or PHA cannot be ascribed to reduced CD28 expression at the time of activation. Treatment of the cells with CADA clearly inhibited the upregulation of $\mathrm{CD} 28$ at later time points post stimulation. This was partially the result of direct CADA-inhibition on CD28 protein expression. The inhibitory effect of CADA on CD28 was not complete, as evident from the residual expression (about $50 \%$ ) in activated cells, but certainly meaningful. Blocking CD28 has been shown to be successful in inhibiting unwanted $\mathrm{T}$ cell

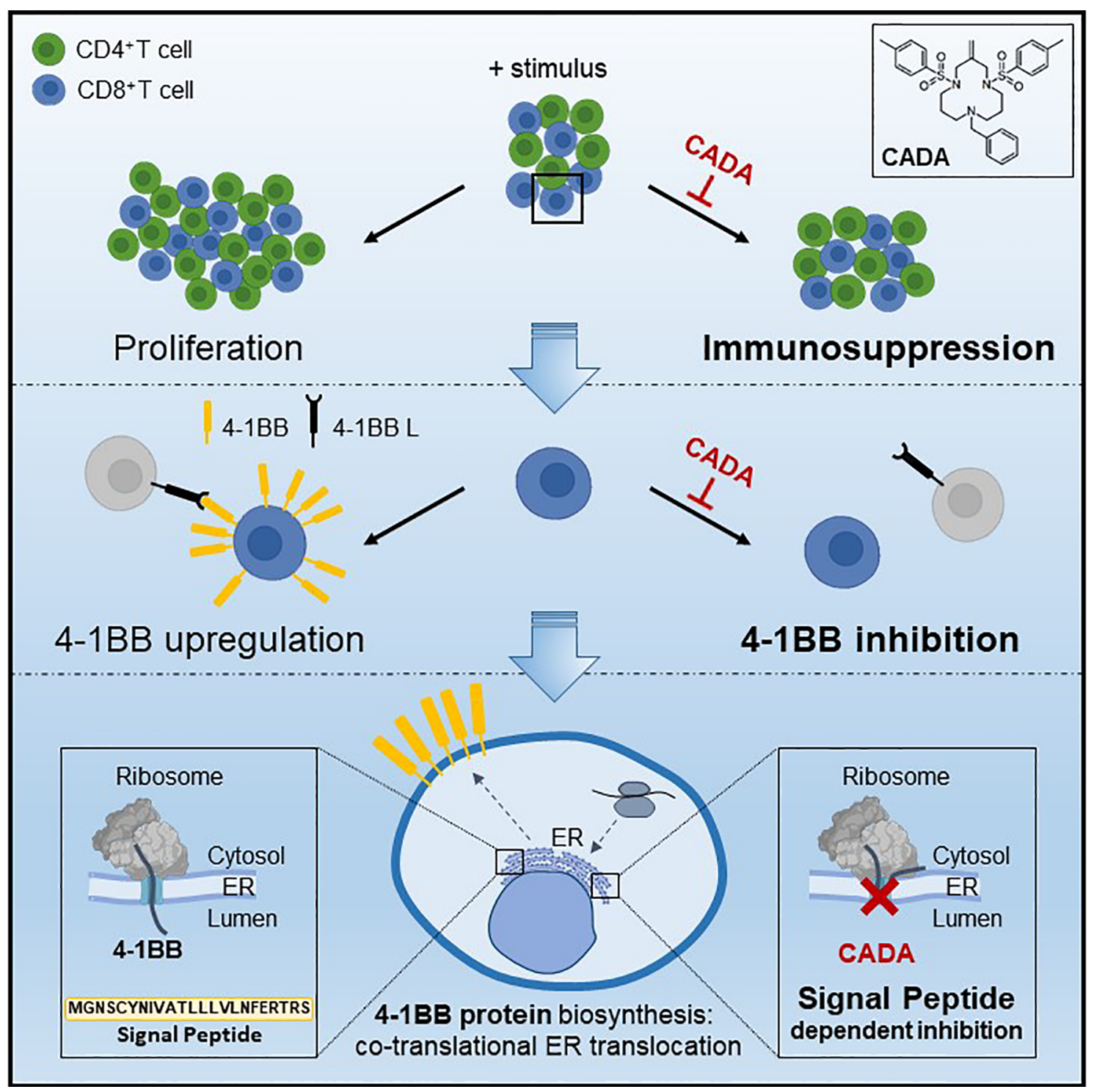

FIGURE 9 | Mode of action of CADA. CADA has immunosuppressive activity mainly on CD8 ${ }^{+} \mathrm{T}$ cells by inhibition of 4-1BB protein biogenesis is a signal peptide-dependent way. 
responses and the use of CADA would circumvent the risk of generating an agonistic signal, as is potentially the case for antiCD28 monoclonal antibodies (52). Also, as 4-1BB is able to replace $\mathrm{CD} 28$ in stimulating high-level IL-2 production by resting $\mathrm{T}$ cells in the absence of CD28 (53-55), the combined inhibition of signaling through CD28 and $4-1 \mathrm{BB}$ by CADA provides an interesting additional effect. Both co-stimulatory factors have sequentially differential roles in the stages of immune response with CD28 involved in the induction stage and $4-1 \mathrm{BB}$ in perpetuating the immune response providing a survival signal for $\mathrm{T}$ cells $(32,56,57)$.

In this study, 4-1BB has been discovered as a new target of CADA. Recently, the role of $4-1 \mathrm{BB}$ agonistic signaling in cancer immunotherapy has received great attention: the effect of 4-1BB stimulation by means of agonistic monoclonal anti-4-1BB antibodies on cytolytic $\mathrm{T}$-cell responses has been used to increase the potency of vaccines against cancers (58-60). Therapeutic use of CADA would imply depletion of 4-1BB in order to attenuate cytotoxic $\mathrm{T}$ cell activity. In this context, blockade of $4-1 \mathrm{BB}$ has been shown to significantly impair the priming of alloantigen-specific $\mathrm{CD}^{+} \mathrm{T}$ cells and to increase allograft survival after transplantation $(42,61)$, thus, suggesting a valuable application for CADA as new immunosuppressive drug in the field of e.g., organ transplantation. Furthermore, in the more general context of inflammatory diseases with a role of the adaptive immunity, general immunosuppression by CADA might be relevant to control, for instance, cytokine storm in hemophagocytic lymphohistiocytosis $(\mathrm{HLH})$, severe cytokine release syndrome (CRS) in CAR $\mathrm{T}$ cell treatment, or even auto-immune diseases. As mainly human targets have been identified for CADA and resistance has been observed for e.g., murine CD4, humanized in vivo animal models are needed to fully evaluate CADA's potential in human disease conditions.

In conclusion (Figure 9), we showed here that the ER translocation inhibitor CADA exerted a profound and consistent in vitro immunosuppressive effect in the MLR and after activation with CD3/CD28 beads, PHA or anti-CD3 Abs. This immunosuppressive effect of CADA involves both $\mathrm{CD} 4^{+}$ and $\mathrm{CD}^{+} \mathrm{T}$ cells, but, is most prominent in the $\mathrm{CD}^{+} \mathrm{T}$ cell subpopulation where it inhibits cell-mediated lympholysis. Next to the full suppression of CD4 and 4-1BB receptor upregulation, the combined effect of CADA on additional co-stimulatory factors such as CD28 and CD8 characterize the total immunosuppressive potential of CADA. Taken together, our

\section{REFERENCES}

1. Maddon PJ, Littman DR, Godfrey M, Maddon DE, Chess L, Axel R. The Isolation and Nucleotide Sequence of a CDNA Encoding the T Cell Surface Protein T4: A New Member of the Immunoglobulin Gene Family. Cell (1985) 42:93-104. doi: 10.1016/S0092-8674(85)80105-7

2. Shaw AS, Amrein KE, Hammond C, Stern DF, Sefton BM, Rose JK. The Lck Tyrosine Protein Kinase Interacts With the Cytoplasmic Tail of the CD4 Glycoprotein Through its Unique Amino-Terminal Domain. Cell (1989) 59:627-36. doi: 10.1016/0092-8674(89)90008-1

3. Pelchen-Matthews A, Boulet I, Littman DR, Fagard R, Marsh M. The Protein Tyrosine Kinase P56lck Inhibits Cd4 Endocytosis by Preventing data justify future in vivo exploration of this compound to evaluate its potential use to repress undesired immune activation.

\section{DATA AVAILABILITY STATEMENT}

The raw data supporting the conclusions of this article will be made available by the authors, without undue reservation.

\section{AUTHOR CONTRIBUTIONS}

KV, EC, BS and SH-B conceived experiments. EC, EP and BP performed experiments. KV, EC and BS wrote the manuscript. DS secured funding. SH-B and DS provided reagents. MW, BS and SH-B provided expertise and feedback. All authors contributed to the article and approved the submitted version.

\section{FUNDING}

This work was partly supported by the KU Leuven grant no. PF/ $10 / 018$. BS is a senior clinical investigator of the Research Foundation Flanders (FWO) (1842919N).

\section{ACKNOWLEDGMENTS}

We thank Anita Camps, Sandra Claes, Eric Fonteyn, Omer Rutgeerts, Geert Schoofs and Joren Stroobants for their excellent technical assistance. Dr. Thomas W. Bell (UNR, Nevada, USA) is acknowledged for providing CADA compound. We are grateful to Prof. Enno Hartmann and Prof. Kai-Uwe Kalies (University Lübeck, Lübeck, Germany) for providing microsomal membranes.

\section{SUPPLEMENTARY MATERIAL}

The Supplementary Material for this article can be found online at: https://www.frontiersin.org/articles/10.3389/fimmu.2021. 650731/full\#supplementary-material

Entry of CD4 Into Coated Pits. J Cell Biol (1992) 117:279-90. doi: 10.1083/ jcb.117.2.279

4. Collman R, Godfrey B, Cutilli J, Rhodes A, Hassan NF, Sweet R, et al. MacrophageTropic Strains of Human Immunodeficiency Virus Type 1 Utilize the CD4 Receptor. J Virol (1990) 64:4468-76. doi: 10.1128/JVI.64.9.4468-4476.1990

5. Rahemtulla A, Fung-Leung WP, Schilham MW, Kundig TM, Sambhara SR, Narendran A, et al. Normal Development and Function of CD8+ Cells But Markedly Decreased Helper Cell Activity in Mice Lacking Cd4. Nature (1991) 353:180-4. doi: 10.1038/353180a0

6. Claeys E, Vermeire K. The CD4 Receptor: An Indispensable Protein in T Cell Activation and a Promising Target for Immunosuppression. Arch Microbiol Immunol (2019) 3:133-50. doi: 10.26502/ami.93650036 
7. Janeway CAJr. The Role of CD4 in T-Cell Activation: Accessory Molecule or Co-Receptor? Immunol Today (1989) 10:234-8. doi: 10.1016/0167-5699(89) 90260-0

8. Konig R, Zhou W. Signal Transduction in T Helper Cells: Cd4 Coreceptors Exert Complex Regulatory Effects on T Cell Activation and Function. Curr Issues Mol Biol (2004) 6:1-15.

9. Krogsgaard M, Li QJ, Sumen C, Huppa JB, Huse M, Davis MM. Agonist/ Endogenous Peptide-MHC Heterodimers Drive T Cell Activation and Sensitivity. Nature (2005) 434:238-43. doi: 10.1038/nature03391

10. Fowell DJ, Magram J, Turck CW, Killeen N, Locksley RM. Impaired Th2 Subset Development in the Absence of CD4. Immunity (1997) 6:559-69. doi: 10.1016/S1074-7613(00)80344-1

11. Cruikshank WW, Greenstein JL, Theodore AC, Center DM. Lymphocyte Chemoattractant Factor Induces CD4-Dependent Intracytoplasmic Signaling in Lymphocytes. J Immunol (1991) 146:2928-34.

12. Bernstein HB, Plasterer MC, Schiff SE, Kitchen CM, Kitchen S, Zack JA. Cd4 Expression on Activated Nk Cells: Ligation of CD4 Induces Cytokine Expression and Cell Migration. J Immunol (2006) 177:3669-76. doi: 10.4049/jimmunol.177.6.3669

13. Bialecki E, Macho Fernandez E, Ivanov S, Paget C, Fontaine J, Rodriguez F, et al. Spleen-Resident CD4+ and CD4- Cd8alpha- Dendritic Cell Subsets Differ in Their Ability to Prime Invariant Natural Killer T Lymphocytes. PloS One (2011) 6:e26919. doi: 10.1371/journal.pone.0026919

14. Schulze-Koops H, Lipsky PE. Anti-CD4 Monoclonal Antibody Therapy in Human Autoimmune Diseases. Curr Dir Autoimmun (2000) 2:24-49. doi: $10.1159 / 000060506$

15. Mayer CT, Huntenburg J, Nandan A, Schmitt E, Czeloth N, Sparwasser T. Cd4 Blockade Directly Inhibits Mouse and Human Cd4(+) T Cell Functions Independent of Foxp3(+) Tregs. J Autoimmun (2013) 47:73-82. doi: 10.1016/ j.jaut.2013.08.008

16. Winsor-Hines D, Merrill C, O’Mahony M, Rao PE, Cobbold SP, Waldmann $\mathrm{H}$, et al. Induction of Immunological Tolerance/Hyporesponsiveness in Baboons With a Nondepleting Cd4 Antibody. J Immunol (2004) 173:471523. doi: 10.4049/jimmunol.173.7.4715

17. Dalgleish AG, Beverley PC, Clapham PR, Crawford DH, Greaves MF, Weiss RA. The CD4 (T4) Antigen is an Essential Component of the Receptor for the AIDS Retrovirus. Nature (1984) 312:763-7. doi: 10.1038/312763a0

18. Klatzmann D, Champagne E, Chamaret S, Gruest J, Guetard D, Hercend T, et al. T-Lymphocyte T4 Molecule Behaves as the Receptor for Human Retrovirus Lav. Nature (1984) 312:767-8. doi: 10.1038/312767a0

19. Vermeire K, Zhang Y, Princen K, Hatse S, Samala MF, Dey K, et al. Cada Inhibits Human Immunodeficiency Virus and Human Herpesvirus 7 Replication by Down-Modulation of the Cellular Cd4 Receptor. Virology (2002) 302:342-53. doi: 10.1006/viro.2002.1624

20. Vermeire K, Bell TW, Choi HJ, Jin Q, Samala MF, Sodoma A, et al. The AntiHIV Potency of Cyclotriazadisulfonamide Analogs is Directly Correlated With Their Ability to Down-Modulate the CD4 Receptor. Mol Pharmacol (2003) 63:203-10. doi: 10.1124/mol.63.1.203

21. Vermeire K, Lisco A, Grivel JC, Scarbrough E, Dey K, Duffy N, et al. Design and Cellular Kinetics of Dansyl-Labeled Cada Derivatives With Anti-HIV and CD4 Receptor Down-Modulating Activity. Biochem Pharmacol (2007) 74:566-78. doi: 10.1016/j.bcp.2007.05.018

22. Vermeire K, Bell TW, Van Puyenbroeck V, Giraut A, Noppen S, Liekens S, et al. Signal Peptide-Binding Drug as a Selective Inhibitor of Co-Translational Protein Translocation. PloS Biol (2014) 12:e1002011. doi: 10.1371/journal. pbio. 1002011

23. Van Puyenbroeck V, Pauwels E, Provinciael B, Bell TW, Schols D, Kalies KU, et al. Preprotein Signature for Full Susceptibility to the Co-Translational Translocation Inhibitor Cyclotriazadisulfonamide. Traffic (2020) 21:250-64. doi: $10.1111 /$ tra. 12713

24. Bell TW, Anugu S, Bailey P, Catalano VJ, Dey K, Drew MG, et al. Synthesis and Structure-Activity Relationship Studies of CD4 Down-Modulating Cyclotriazadisulfonamide (Cada) Analogues. J Med Chem (2006) 49:1291312. doi: 10.1021/jm0582524

25. Vermeire K, Allan S, Provinciael B, Hartmann E, Kalies KU. RibonucleaseNeutralized Pancreatic Microsomal Membranes From Livestock for in Vitro Co-Translational Protein Translocation. Anal Biochem (2015) 484:102-4. doi: 10.1016/j.ab.2015.05.019
26. Hepburn TW, Totoritis MC, Davis CB. Antibody-Mediated Stripping of CD4 From Lymphocyte Cell Surface in Patients With Rheumatoid Arthritis. Rheumatol (Oxford England) (2003) 42:54-61. doi: 10.1093/rheumatology/ keg030

27. Martin E, Palmic N, Sanquer S, Lenoir C, Hauck F, Mongellaz C, et al. Ctp Synthase 1 Deficiency in Humans Reveals Its Central Role in Lymphocyte Proliferation. Nature (2014) 510:288-92. doi: 10.1038/nature13386

28. Weinberg AD. Ox40: Targeted Immunotherapy - Implications for Tempering Autoimmunity and Enhancing Vaccines. Trends Immunol (2002) 23:102-9. doi: 10.1016/s1471-4906(01)02127-5

29. Lane P. Role of OX40 Signals in Coordinating Cd4 T Cell Selection, Migration, and Cytokine Differentiation in T Helper (Th)1 and Th2 Cells. J Exp Med (2000) 191:201-6. doi: 10.1084/jem.191.2.201

30. Shuford WW, Klussman K, Tritchler DD, Loo DT, Chalupny J, Siadak AW, et al. 4-1bb Costimulatory Signals Preferentially Induce Cd8+ T Cell Proliferation and Lead to the Amplification in Vivo of Cytotoxic T Cell Responses. J Exp Med (1997) 186:47-55. doi: 10.1084/jem.186.1.47

31. Vinay DS, Kwon BS. Role of 4-1BB in Immune Responses. Semin Immunol (1998) 10:481-9. doi: 10.1006/smim.1998.0157

32. Kwon B, Moon CH, Kang S, Seo SK, Kwon BS. 4-1bb: Still in the Midst of Darkness. Mol Cells (2000) 10:119-26. doi: 10.1007/s10059-000-0119-0

33. Wickner W, Schekman R. Protein Translocation Across Biological Membranes. Science (2005) 310:1452-6. doi: 10.1126/science.1113752

34. von Heijne G. Signal Sequences. The Limits of Variation. J Mol Biol (1985) 184:99-105. doi: 10.1016/0022-2836(85)90046-4

35. Rapoport TA. Protein Translocation Across the Eukaryotic Endoplasmic Reticulum and Bacterial Plasma Membranes. Nature (2007) 450:663-9. doi: 10.1038/nature06384

36. Hegde RS, Kang SW. The Concept of Translocational Regulation. J Cell Biol (2008) 182:225-32. doi: 10.1083/jcb.200804157

37. Marrack P, Kappler J. The Staphylococcal Enterotoxins and Their Relatives. Science (1990) 248:705-11. doi: 10.1126/science.2185544

38. Killeen N, Davis CB, Chu K, Crooks ME, Sawada S, Scarborough JD, et al. Cd4 Function in Thymocyte Differentiation and T Cell Activation. Philos Trans $R$ Soc London Ser B Biol Sci (1993) 342:25-34. doi: 10.1098/rstb.1993.0131

39. Mould DR, Davis CB, Minthorn EA, Kwok DC, Elliott MJ, Luggen ME, et al. A Population Pharmacokinetic-Pharmacodynamic Analysis of Single Doses of Clenoliximab in Patients With Rheumatoid Arthritis. Clin Pharmacol Ther (1999) 66:246-57. doi: 10.1016/s0009-9236(99)70032-9

40. Reddy MP, Kinney CA, Chaikin MA, Payne A, Fishman-Lobell J, Tsui P, et al. Elimination of Fc Receptor-Dependent Effector Functions of a Modified Igg4 Monoclonal Antibody to Human Cd4. J Immunol (2000) 164:1925-33. doi: 10.4049/jimmunol.164.4.1925

41. Xiao Z, Mescher MF, Jameson SC. Detuning CD8 T Cells: Down-Regulation of CD8 Expression, Tetramer Binding, and Response During CTL Activation. J Exp Med (2007) 204:2667-77. doi: 10.1084/jem.20062376

42. Wang J, Guo Z, Dong Y, Kim O, Hart J, Adams A, et al. Role of 4-1BB in Allograft Rejection Mediated by CD8+ T Cells. Am J Transpl (2003) 3:543-51. doi: 10.1034/j.1600-6143.2003.00088.x

43. Cannons JL, Lau P, Ghumman B, DeBenedette MA, Yagita H, Okumura K, et al. 4-1bb Ligand Induces Cell Division, Sustains Survival, and Enhances Effector Function of CD4 and CD8 T Cells With Similar Efficacy. J Immunol (2001) 167:1313-24. doi: 10.4049/jimmunol.167.3.1313

44. Lin W, Voskens CJ, Zhang X, Schindler DG, Wood A, Burch E, et al. FcDependent Expression of CD137 on Human Nk Cells: Insights Into "Agonistic" Effects of Anti-CD137 Monoclonal Antibodies. Blood (2008) 112:699-707. doi: 10.1182/blood-2007-11-122465

45. Kwon BS, Weissman SM. Cdna Sequences of Two Inducible T-Cell Genes. Proc Natl Acad Sci USA (1989) 86:1963-7. doi: 10.1073/pnas.86.6.1963

46. Melero I, Bach N, Hellström KE, Aruffo A, Mittler RS, Chen L. Amplification of Tumor Immunity by Gene Transfer of the Co-Stimulatory 4-1bb Ligand: Synergy With the CD28 Co-Stimulatory Pathway. Eur J Immunol (1998) 28:1116-21. doi: 10.1002/(sici)1521-4141(199803)28:03<1116::Aid-immul116>3.0.Co;2-a

47. Kwon BS, Hurtado JC, Lee ZH, Kwack KB, Seo SK, Choi BK, et al. Immune Responses in 4-1BB (CD137)-Deficient Mice. J Immunol (2002) 168:5483-90. doi: 10.4049/jimmunol.168.11.5483

48. Alosaimi MF, Hoenig M, Jaber F, Platt CD, Jones J, Wallace J, et al. Immunodeficiency and EBV-induced Lymphoproliferation Caused by 4-1BB 
Deficiency. J Allergy Clin Immunol (2019) 144:574-83 e5. doi: 10.1016/j.jaci. 2019.03.002

49. Van Puyenbroeck V, Claeys E, Schols D, Bell TW, Vermeire K. A Proteomic Survey Indicates Sortilin as a Secondary Substrate of the ER Translocation Inhibitor Cyclotriazadisulfonamide (Cada). Mol Cell Proteomics (2017) 16:157-67. doi: 10.1074/mcp.M116.061051

50. Reddy VV, Myles A, Cheekatla SS, Singh S, Aggarwal A. Soluble CD25 in Serum: A Potential Marker for Subclinical Macrophage Activation Syndrome in Patients With Active Systemic Onset Juvenile Idiopathic Arthritis. Int J Rheumatic Dis (2014) 17:261-7. doi: 10.1111/1756-185x.12196

51. Shatrova AN, Mityushova EV, Vassilieva IO, Aksenov ND, Zenin VV, Nikolsky NN, et al. Time-Dependent Regulation of IL-2R alpha-Chain (Cd25) Expression by TCR Signal Strength and IL-2-Induced Stat5 Signaling in Activated Human Blood T Lymphocytes. PloS One (2016) 11: e0167215. doi: 10.1371/journal.pone.0167215

52. Beyersdorf N, Kerkau T, Hunig T. Cd28 Co-Stimulation in T-Cell Homeostasis: A Recent Perspective. ImmunoTarg Ther (2015) 4:111-22. doi: $10.2147 /$ itt.s61647

53. Chu NR, DeBenedette MA, Stiernholm BJ, Barber BH, Watts TH. Role of IL12 and 4-1BB Ligand in Cytokine Production by CD28+ and CD28- T Cells. J Immunol (1997) 158:3081-9.

54. DeBenedette MA, Shahinian A, Mak TW, Watts TH. Costimulation of CD28T Lymphocytes by 4-1BB Ligand. J Immunol (1997) 158:551-9.

55. Saoulli K, Lee SY, Cannons JL, Yeh WC, Santana A, Goldstein MD, et al. CD28-Independent, TRAF2-dependent Costimulation of Resting T Cells by 4-1BB Ligand. J Exp Med (1998) 187:1849-62. doi: 10.1084/jem.187.11.1849

56. Takahashi C, Mittler RS, Vella AT. Cutting Edge: $4-1 \mathrm{BB}$ is a Bona Fide Cd8 T Cell Survival Signal. J Immunol (1999) 162:5037-40.
57. Hurtado JC, Kim YJ, Kwon BS. Signals Through 4-1BB are Costimulatory to Previously Activated Splenic T Cells and Inhibit Activation-Induced Cell Death. J Immunol (1997) 158:2600-9.

58. Bartkowiak T, Curran MA. 4-1bb Agonists: Multi-Potent Potentiators of Tumor Immunity. Front Oncol (2015) 5:117. doi: 10.3389/fonc.2015.00117

59. Chester C, Ambulkar S, Kohrt HE. 4-1bb Agonism: Adding the Accelerator to Cancer Immunotherapy. Cancer Immunol Immunother (2016) 65:1243-8. doi: 10.1007/s00262-016-1829-2

60. Oda SK, Anderson KG, Ravikumar P, Bonson P, Garcia NM, Jenkins CM, et al. A Fas-4-1BB Fusion Protein Converts a Death to a Pro-Survival Signal and Enhances T Cell Therapy. J Exp Med (2020) 217(12):e20191166. doi: 10.1084/jem.20191166

61. Cho HR, Kwon B, Yagita H, La S, Lee EA, Kim JE, et al. Blockade of 4-1BB (Cd137)/4-1bb Ligand Interactions Increases Allograft Survival. Transplant Int Off J Eur Soc Organ Transpl (2004) 17:351-61. doi: 10.1007/s00147-0040726-3

Conflict of Interest: The authors declare that the research was conducted in the absence of any commercial or financial relationships that could be construed as a potential conflict of interest.

Copyright (๔) 2021 Claeys, Pauwels, Humblet-Baron, Provinciael, Schols, Waer, Sprangers and Vermeire. This is an open-access article distributed under the terms of the Creative Commons Attribution License (CC BY). The use, distribution or reproduction in other forums is permitted, provided the original author(s) and the copyright owner(s) are credited and that the original publication in this journal is cited, in accordance with accepted academic practice. No use, distribution or reproduction is permitted which does not comply with these terms. 